IZA DP No. 8260

\title{
Early Retirement and Post Retirement Health
}

Daniel Hallberg

Per Johansson

Malin Josephson

June 2014 


\title{
Early Retirement and Post Retirement Health
}

\author{
Daniel Hallberg \\ Swedish Social Insurance Inspectorate (ISF) \\ and UCLS \\ Per Johansson \\ Uppsala University, \\ UCLS, IFAU, ISF and IZA \\ Malin Josephson \\ Swedish Social Insurance Inspectorate (ISF) \\ and University of Uppsala
}

\section{Discussion Paper No. 8260 \\ June 2014}

\author{
IZA \\ P.O. Box 7240 \\ 53072 Bonn \\ Germany \\ Phone: +49-228-3894-0 \\ Fax: +49-228-3894-180 \\ E-mail: iza@iza.org
}

\begin{abstract}
Any opinions expressed here are those of the author(s) and not those of IZA. Research published in this series may include views on policy, but the institute itself takes no institutional policy positions. The IZA research network is committed to the IZA Guiding Principles of Research Integrity.

The Institute for the Study of Labor (IZA) in Bonn is a local and virtual international research center and a place of communication between science, politics and business. IZA is an independent nonprofit organization supported by Deutsche Post Foundation. The center is associated with the University of Bonn and offers a stimulating research environment through its international network, workshops and conferences, data service, project support, research visits and doctoral program. IZA engages in (i) original and internationally competitive research in all fields of labor economics, (ii) development of policy concepts, and (iii) dissemination of research results and concepts to the interested public.
\end{abstract}

IZA Discussion Papers often represent preliminary work and are circulated to encourage discussion. Citation of such a paper should account for its provisional character. A revised version may be available directly from the author. 


\section{ABSTRACT}

\section{Early Retirement and Post Retirement Health*}

This paper studies empirically the consequences of retirement on health. We make use of a targeted retirement offer to army employees 55 years of age or older. Before the offer was implemented in the Swedish defense, the normal retirement age was 60 years of age. Estimating the effect of the offer on individuals' health within the age range 56-70, we find support for a reduction in both mortality and in inpatient care as a consequence of the early retirement offer. Increasing the mandatory retirement age may thus not only have positive government income effects but also negative effects on increasing government health care expenditures.

JEL Classification: J22, J26, I18

Keywords: health, mortality, inpatient care, retirement, health care, pensions, occupational pensions

Corresponding author:

Per Johansson

Department of Economics

Uppsala University

Box 513

75120 Uppsala

Sweden

E-mail: per.johansson@ifau.uu.se

\footnotetext{
* We are grateful to Marcus Eliasson, Peter Nilsson and Helena Holmlund for their very useful comments on an earlier version of the paper. Comments from seminar participants at Uppsala Center for Labor Studies (UCLS), Linnaeus University and the Swedish Social Insurance Inspectorate (ISF) are also gratefully acknowledged. Johansson acknowledges the financial support from Forte Financial support (DNR 2013-2482)
} 


\section{Introduction}

Demographic projections clearly show that the population in most OECD countries is ageing, and that the working-age population as a share of the total population will decrease. This development will exert pressure on government budgets. This is both because a larger fraction of elderly people will create greater demand for welfare services and also because each potential taxpayer will have more non-workers to support. As a consequence, most OECD countries are undertaking measures to prolong the careers of older workers. However, a natural question - which has been largely overlooked by policy makers - concerns the effect of postponing retirement, on individual well-being and, in particular, on health. Unfavorable (or favorable) effects from retirement timing on health may not only influence individual wellbeing, but also have direct effects on health care costs in society.

The aim of this study is to enhance the understanding of the consequences of voluntary retirement on health. To this end, we make use of detailed longitudinal data on inpatient care and mortality. In order to identify the causal effect of retirement timing on subsequent health, we make use of a targeted retirement offer, implemented during 1992-1994, to army employees 55 years of age or older (explained in detail below). Before this offer was instigated, the normal retirement age was 60 years of age for regular military officers. The motivation behind the targeted retirement offer was the need to rejuvenate staff in order to better serve the future needs of the Swedish defense. As a result, early retirement for employees 55 years of age or older was offered in negotiated agreements. We aim to estimate the effect of this early retirement offer on the health of individuals who accepted this offer between the ages of 55-59 years, by examining their subsequent health from ages 56-70. The identification strategy is based on cohort variation in the timing of the offer and by using other civil servants not affected by the early retirement offer to control for secular trends in schooling, nutrition (i.e. early childhood difference at the cohort level), health care technology, and general period effects.

We show that the targeted offer increased early voluntary retirement and decreased market work. Moreover, the targeted offer had no effect on disposable income after the regular retirement age of 60 . We find that the opportunity to retire early reduced the number of days of inpatient care. The results are robust to the model specification. We also find a lower risk of mortality for those who retired early.

From a heterogeneity analysis we find a greater reduction in inpatient care days for 
those with low pre-retirement incomes and low education. One interpretation of this could be that the effect is linked to less stress and less exposure to workplace hazards. A second heterogeneity analysis, using different causes of death and number of days in inpatient care due to different diagnoses, gives some support to a reduced risk of dying from acute myocardial infarction.

The rest of the paper is structured as follows. Section 2 provides a discussion of the earlier literature. Section 3 discusses the Swedish pension system. Section 4 describes the early retirement reform. Section 5 discusses the methodological framework, the data analyzed in this study, and the sample selections made. Section 6 provides the analyses. Section 7 discusses the findings regarding effects of retirement on health. Section 8 concludes the study.

\section{Earlier literature}

Cross-sectional analyses usually find that those who retire early have worse postretirement health. ${ }^{1}$ Taking these studies as evidence of a positive effect on the health of later retirement suggests a "win-win" situation of prolonging or extending retirement age in the population. However, the results from cross-sectional studies are questionable, as individual decisions to retire are most likely influenced by health reasons. That is, the population sector that retires early has worse health in general than the population sector that retires later.

Now, though, there is an emerging literature, using data from both Europe and the US, that deals with the potential problem of selection that uses longitudinal data and quasi-experimental designs (e.g., Neuman, 2007; Bound \& Waidmann, 2008; Coe \& Lindeboom, 2008; Westerlund et al., 2009; Vahtera et al., 2009; Coe \& Zamarro, 2011; Hernaes et al., 2013; Kuhn et al., 2010; Bloemen et al., 2013). The general result from these studies suggests a positive effect of early retirement on health, at least when self-reported measures on health are used to assess health. For instance, the longitudinal studies by Westerlund et al. (2009) and Vahtera et al. (2009) find

\footnotetext{
${ }^{1}$ An exception is Hult et al. (2010), who found no effect on mortality. Their study is based on a cohort of male construction workers. They exclude individuals with diagnoses normally connected to increased mortality. For the remaining individuals, they compare the increased risk of those entering early retirement against those who are still working. Hult et al. (2010) have detailed information on individuals' health before (potential) retirement and use longitudinal data. However, since they use death as a health outcome, they have no possible way to use the longitudinal aspect of the data.
} 
positive effects based on self-reported health measures on mental and physical fatigue, depressive symptoms, and a decrease in sleep disturbances. However, studies using self-reported health measures in a longitudinal design may also have problems, since answers to questions about health may vindicate the active choice of retiring. Using the same data as in Westerlund et al. (2009) and Vahtera et al. (2009), ${ }^{2}$ Westerlund et al. (2010) could not, for instance, find a positive effect of retirement on respiratory diseases, diabetes, coronary heart disease, or stroke.

An exception to the general result is Kuhn et al.'s study (2010), which finds negative effects on health (measured as mortality before age 67 ) of early retirement for men. In the estimation, the researchers exploit changes in unemployment rules that allowed workers to retire early in some regions in Austria. Coe and Lindeboom (2008) find a positive effect on self-reported health. Their study concerns an offer of early retirement from the employer, as an instrument for actual retirement. Hernaes et al. (2013) use a series of retirement policy changes in Norway, which reduced the retirement age for one group of workers but not for others. They find no effect on mortality of retirement age. Coe and Zamarro (2011) use European cross-national data and exploit country variation in legislated (normal) pension age and legislated early retirement age as instruments for retiring. They find positive effects on health from retirement Charles (2002) and Neuman (2007) use the incentives imbedded in the US Social Security regulations at certain ages, as an exogenous shift in retirement probability. The identifying assumption is hence that there are no sudden changes in health at those ages for reasons other than retirement. Charles (2002) finds a positive effect on mental well-being. Neuman (2007) finds a positive effect on subjective health but no effect on objective measures. Bound and Waidmann (2008) employ a similar method to institutional features in the UK pension system. They find an indication of a positive health effect of retirement for men. Bloemen et al. (2013) focus on a group of civil servants who became eligible for retirement earlier than expected during a short time window. They find that early retirement decreased mortality for men.

This study and similar studies of the effects of retirement on subsequent health relate closely to the field of literature (by now, quite large) on the health effects of job loss (e.g., Eliason \& Storrie, 2009a, 2009b, 2010; Browning \& Heinesen, 2012; Black et al., 2013). All things considered, the evidence suggests that there are considerable

\footnotetext{
${ }^{2}$ That is, the French Gazel cohort. This is a yearly panel that includes, among others, self-reported measures on health 7 years before to 7 years after retirement at the age of 55-60.
} 
adverse health effects from losing a job and becoming unemployed. However, for several reasons, the effects of unemployment most likely differ from the effects of (voluntary) retirement. First, unlike unemployment, retirement is likely to have a smaller impact on the disposable income, especially in the long run. That is, income loss due to early retirement presumably has a smaller effect on income later in life than (longterm) unemployment. The early retirement program investigated in this study left the retirement income at normal retirement age unchanged, given that the individual had a full record of 30 years of service. Second, one can assume that it is much more stressful to become unemployed than to enter retirement, since being unemployed may impose a social stigma different from that of retirement. Unplanned "retirement" (via unemployment) may furthermore be stressful because of uncertainty about the future, which in turn may reduce the possibility to invest in one's own health.

\section{The Swedish pension system ${ }^{3}$}

The public pension system for the cohorts under study was mainly ${ }^{4}$ a defined benefit scheme consisting of a flat-rate basic pension and an income-related supplementary pension based on the best 15 out of 30 years of earnings. ${ }^{5}$ The normal pension age was 65. In case of early (or late) retirement via the national pension system, the replacement rates were reduced (increased) through actuarial adjustments.

Most workers have supplementary pensions via occupational pension schemes, formed through collective agreements by the unions and employers' federations. The public system has a cap, which was 333,750 SEK in 2013 prices (about 38,000 Euro) at the time of the reform. ${ }^{6}$ For most employees, incomes above the cap are covered by occupational pensions. There exist four large collectively-agreed occupational pension

\footnotetext{
${ }^{3}$ A more detailed description of the Swedish institutions is provided in the Appendix.

${ }^{4} \mathrm{~A}$ new pension scheme was phased in in 1998. Individuals born 1938-1953 are in both the new and the old schemes. Those born 1938 had 16/20 (those born 1939 had 15/20) of their national pension from the old system. Thus the cohorts studied here - born 1931 to 1939 - receive public pensions mainly from the old system.

${ }^{5}$ For those with fewer than 30 years of service, the benefit was reduced proportionally.

${ }^{6}$ The cap was linked to prices and was 7.5 times the price base amount (PBA). The price base amount is determined by the government each year and follows the price level. In 2013 the PBA was 44,500 SEK (5,170 Euro). The price base amount is used for indexation of the compensation levels in nominal kronor, for the majority of benefits in the Swedish social insurance system. Since 2003 the cap has instead been linked to incomes and is 7.5 times the income base amount (IBA). In 2013 the IBA was 56,600 (6,576 Euro) and the cap was 424,500 SEK in 2013 prices (48,000 Euro).
} 
systems: (i) central government employees, (ii) local government employees, (iii) privately employed white-collar workers, and (iv) privately employed blue-collar workers. For central government employees in the period studied here, these pensions awarded extra pension income amounting to about 10 percent of additional income replacement for income below the cap, and about 65 percent for income above the cap. ${ }^{7}$ For a large share of civil servants, the occupational pensions are important for the income in their old age. ${ }^{8}$

Generally the occupational pensions offer relatively favorable possibilities for early retirement. During the period under study, several professions, particularly in the public sector, had a normal retirement age below the national retirement age of 65 as part of the collective agreement. Those employees, including military employees, retired with incomes from occupational pensions only, thus postponing the start of public pension withdrawal to the $65^{\text {th }}$ birthday. For central government employees with full earnings history (30 years), the level of compensation in early retirement was about 65 percent of earnings (for those with less than 30 years of service the benefit was reduced proportionally). Since public pension withdrawal was postponed until age 65 , retirement with occupational pension implied no cost in terms of reduced public pension benefits after age 65 .

\section{The reform: the defense bill in 1992}

The defense bill was taken by the Swedish Parliament in February 1992 and covered the years 1992 to 1997 (Prop. 1991/92:102, p 102). The defense bill declared that the Swedish military defense needed structural changes that required the personnel to be better trained. It was, furthermore, stated that the number of personnel in the Armed Forces were to be reduced by more than 1,500 regular military officers, more than 4,500 civilian employees, and approximately 1,200 reserve officers (Prop. 1991/92:102, p. 86). The reduction in personnel was estimated to be completed by the end of 1994. In particular it was stated that "the age structure of professional

\footnotetext{
${ }^{7}$ Blue-collar workers only had extra pension income below the cap from their collective agreement.

${ }^{8}$ For the importance of this with regard to our studied population, see the data description. Försäkringskassan (2012) shows that occupational pensions have become more important over time. For instance, about 15 percent, 30 percent, and 50 percent of all 50-59 year olds (independently of profession) had incomes above the cap of 7.5 times the PBA in 1991, 2001, and 2010, respectively. Försäkringskassan (2012) also shows that for military personnel between the ages 28-64, almost 80 percent had incomes above the cap in 2010 .
} 
officers should be changed and adopted to better meet the needs of the defense forces of younger officers [own translation]" (Prop. 1991/92:102, p.86). To adopt the age structure of the officers, it was suggested that the reduction in personnel should be solved by collective agreement arrangements, providing beneficial conditions for older personnel to take an early retirement (SOU 1991: 87).

Via their employment contracts, the majority of military officers had strong employment protection ("fullmaktsanställning"), which meant that they could not be dismissed due to redundancy. The targeted early retirement offer was voluntary for the individual to accept. The bill states that there was a need for extraordinary measures in order to encourage individuals to retire voluntarily. The bill states that severance pay or leave of absence with full pay could be used for those aged 55 or older. This means that those military officers who did not accept the early retirement offer could be granted leave of absence with full pay.

The previous defense bill in 1986 (prop. 1986/87:95) declared that the workforce in the Armed Forces were undersized. Contrary to the subsequent bill, it stated that more recruits were needed and early retirement needed to be reduced. There is no statement regarding rejuvenation or a need for structural changes as regards to the personnel, except the requirement that the personnel were to be better trained.

Table 1 provides an overview of ages, years and birth cohorts that were affected by the 1992 Defense Bill. Birth cohorts 1931 and 1932 are not affected by the Bill. Birth cohorts 1933-1937 were partly affected, and birth cohorts 1938-1939 were fully affected, i.e., from the age of 55. The reform was implemented during 1992, which means that the birth cohort 1933 may also have been affected. Therefore, for our main analysis, we will discard the birth cohorts 1933-1937. Under the Bill, the estimated personnel reduction was expected to take about 2 years.

\section{Methodological framework and data}

The interest is in estimating the effects from the Bill that gave the cohorts born 19381939 the possibility of retiring at the age of 55 instead of at 60 . As measurements of health we have hospital admissions and mortality. We make use of the cohorts born 1931-1932 in the estimation of the counterfactual health of those born 1938-1939. One crux of using the cohort variation in the estimation is that there may be health differences at the same age across the cohorts, for instance stemming from differences 
in the upbringing. The studied cohorts were young during World War II, and even though the circumstances in Sweden were not at all comparable to the rest of Europe, this could have had long consequences for the health of the younger cohorts especially. ${ }^{9}$ Another potential problem is technological improvement in health care from which the younger cohort gains more than the older. In order to take into account these potential differences in health at a given age across cohorts, we make use of male ${ }^{10}$ government employees, other than military personnel, to estimate the potential cohort effect. That is, the effect on one's health of being offered early retirement can be estimated using the following, difference-in-difference, regression model:

$$
E\left(H_{a} \mid M, C_{38-39}\right)=g\left(\alpha_{0}+\alpha_{1} C_{38-39} M+\alpha_{2} C_{38-39}+\alpha_{3} M\right)
$$

Here $g$ is an unknown functional form, $H_{a}$ is the health at age $56 \leq a \leq 70, C_{38-39}$ is 1 (0 else) if the individual is born 1938-1939, $M$ is 1 ( 0 else) if the individual was a military employee at age 54 and $E$ is the expectation operator. The Greek letters are parameters that will be estimated. Here $\alpha_{1}$ measures the effect of the reform given that in the absence of the reform the health of military personnel born 1938-1939 is equal to the health of other government employees born 1938-1938. The model allows for a potential parallel shift for military personnel. The assumption thus implies that, in the absence of the 1992 Bill any trend in health or consumption of health care during ages 56-70 should be the same for both military and non-military government male employees. Since we have data on inpatient care for the two groups of civil servants before the age of 55 the assumption is informally tested in section 6.1 by studying the trends in the health of non-military government employees against the trends of military government employees before the age of 55 .

\subsection{Data and sampling}

Our empirical analysis exploits micro data originating from administrative registers maintained by Statistics Sweden. Our data cover the entire Swedish population aged 16-65 during the period 1985-1999, and individuals aged 16-74 during the period 2000-2010. The data contain annual information on a wide range of educational and demographic characteristics as well as different income sources: income from work, pensions, social security benefits, and disposable income.

\footnotetext{
${ }^{9}$ Cf. Victora et al. (2008).

${ }^{10}$ The reason for sampling only men is that no women military personnel exist for these cohorts
} 
We sample all males born in the period 1931-1939 who were civil servants at the age of 54 years, i.e., employed in the central government sector. This provides the panel of interest from which we can observe all inpatient visits for relevant birth cohorts from age 56 until 70. We observe all death until 2010, which means that the survival time of the cohort born in 1931 is censored at the age of 79, while the survival time of the cohort born in 1939 is censored at the age of 71 .

Information on hospitalizations and the causes of death for the period 1961-2010 was provided by the National Board of Health and Welfare and covers all inpatient medical contacts at public hospitals from 1987 through 1996. This is no major restriction since virtually all medical care in Sweden at that time was performed by public agents. From 1997 onward, the register also includes privately operated health care. In order for an individual to be registered with a diagnosis, (s)he must have been admitted to a hospital. As a general rule, this means that the person has to spend the night at the hospital. However, starting in 2002 the registers also cover outpatient medical contacts in specialized care. In this analysis we restrict outcomes in hospitalization to inpatient care (i.e., hospital nights).

We use three measures of labor market status at 55-59 years of age. All measures make use of data from LOUISE (or SYS), administrated by Statistics Sweden. The first and primary measurement is prevalence of occupational pensions between the ages 55 to $59^{11}$ The two alternative measures used in sensitivity analyses are i) prevalence of labor market earnings larger than one price base amount (PBA) ${ }^{12}$ and ii) gainful employment in November each year as registered in administrative registers (RAMS, Statistics Sweden), following the definition used by the International Labour Organization (ILO). The ILO definition means that all who performed gainful work for at least one hour per week are considered employed.

Income is measured in several ways. Disposable income is net-of-tax income from work, capital, and social security income (in Sweden many of these benefits are subject

\footnotetext{
${ }^{11}$ There are data limitations with regard to pensions, since these data started in 1990. This means that we do not have complete information on pensions before age 59 (58) for the oldest cohort born 1931 (1932). However, since it is very unlikely that individuals with take-up of pensions stopped receiving their pensions in a subsequent year (except due to death), we can safely impute individual pension take-up using the information given in 1990. We do this imputation in ages 55-58 for cohorts 1931 and for ages 55-57 for cohort 1932. This imputation does not affect our measure of labor market status based on the take-up of occupational pension in the age span 55-59 but improves our knowledge regarding the exact age when take-up started before age 60 .

${ }^{12}$ In 2013 the PBA was 44,500 SEK (5,170 Euro).
} 
to income tax), combined with social benefits and transfers. Due to the age restriction on our population (i.e., 16-65 during 1987-1999 and 16-74 during 2000-2010), there is a gap in data on disposable income for cohorts $1931-1934 .{ }^{13}$ We impute the missing data by making a linear approximation between the last observation before year 2000 and year 2000, when we start observing the disposable income again (at least, until the person exits the population via death or emigration). Labor income is measured as income from work and entrepreneurship before income tax.

Table 2 provides some descriptive statistics for our analysis population. From this table we can see that on average, military employees have higher labor incomes at age 54 and that the income distribution of the military is more compressed than that of the other government employees. On the other hand, disposable income at age 59 is relatively similar across groups. As mentioned above, large shares of civil servants have income above the income cap in the public pension system. We find that for military personal born 1931-1932 and 1938-1939 respectively, 23 percent and 55 percent had labor incomes above the cap at age 54. For other civil servants, the corresponding shares are 18 percent and 33 percent respectively. The fraction of occupational pension recipients at ages 55-59 is, as expected, higher for military employees born 1938-39, compared to other government employees and older military personnel. Alternative measures of employment (i.e., prevalence of labor market earnings larger than one price base amount and being registered as gainfully employed in administrative registers) show that employment is lower for military employees born 1938-39, compared to other government employees and older military personnel. Military employees have on average a longer education period than the non-military employees. The majority of military employees have a college degree (i.e., post-secondary 2 years or more). Obviously the variance is much larger for the non-military employees.

The table shows furthermore that the average number of days in inpatient care (at ages 56-70, 56-60, and 61-70) is higher for older cohorts of military employees compared to the same cohorts of other civil servants, but lower for younger cohorts of military personnel compared to the same cohorts of other civil servants. A raw difference-indifference estimate suggests a statistically significant reduction of 8.11 days for the younger cohort. There is no difference across military and non-military employees with regard to the probability of having any inpatient care visits (70 and 65 percent for the

\footnotetext{
${ }^{13}$ For the 1931 cohort the disposable income at ages 66-69 are not observed, and for those born 1932, the disposable income at the ages 66-68 are not observed.
} 
1931-1932 and 1938-1939 cohorts respectively). From the second row from the end, where the fraction of the dead is presented, we can see a reduction of mortality over time for both groups of civil servants. However, this reduction is larger among military employees.

\section{Analysis}

In this section we first show the impact of the reform on early retirement and labor supply. In sections 6.2 and 6.3 we then present the results for days in inpatient care and mortality respectively. In order to gain an understanding about possible causes to the effects described in section 6.2 and 6.3 , section 6.4 provides an analysis of heterogeneous treatment effects. Section 6.5 provides a sensitivity analysis in which we discuss results from alternative morbidity outcomes.

\subsection{The impact of the reform on early retirement and labor supply}

The fraction (given as a percentage) of individuals entering occupational pensions at a given age, from the government employees born 1931-1940, is displayed in Figure 1. ${ }^{14}$ The age-specific incidence for the military personnel is displayed in the left panel and the incidence for the nonmilitary employees is displayed in the right panel. From this figure, we can see that for the 1931 cohort, more than 60 percent of the military employees received an occupational pension at the age of 60 and that around 10 percent received it at the age of 55 .

For the other civil servants from the same birth cohort, the corresponding numbers are around 10 percent for both ages. However, what is most interesting in the figure is the dramatic variation across cohorts in age, when entering occupational pension within the military. This is not the case among the other civil servants. The most striking variation is that more than 60 percent of the military employees born 19381939 entered retirement at the age of 55, while between 5 to 10 percent only of the cohorts born 1931-1932 did. The most prevalent age of retirement for the non-military

\footnotetext{
${ }^{14}$ The 1940 cohort is included in the figure primarily to show the temporariness of the reform. As mentioned previously, the reduction in personnel was expected to be completed already by 1994; hence, this cohort was not given the same opportunities as the older cohorts. This is also clearly visible in the figure.
} 
employees across all cohorts is between the ages 61-64; the second most common age of occupational pension incidence is age 65 . For the non-military there is a rather stable fraction of retirees at age 60 , while there is a tendency toward an increase in the fraction receiving occupational pensions at 56-59 years of age.

In order to provide further graphical evidence of the relevance of the reform, we display the probability of having occupational pensions, of having labor income, and of being registered as gainfully employed according to the ILO definition, for the cohorts 1938-1939 and 1931-1932 for both military and non-military government employees in Figure 2, Figure 3, and Figure 4 respectively. From these figures it is clear that the Defense Bill affected the fraction that received occupational pensions, thereby also affecting the age of retirement (measured as the leap in either the take-up rate of occupational pension or fraction employed) for the military personnel born 1938-1939. There is no similar discontinuity for the same cohorts among the non-military government employees. Furthermore, the alternative measures of labor market status tell the same story.

The estimates of $b_{1 a}$ from the following regression model

$$
D_{i a}=b_{0 a}+b_{1 a} C_{i 38-39} M_{i}+b_{2 a} C_{i 38-39}+b_{3 a} M_{i}+\varepsilon_{i a}, \quad a=55, \ldots, 70
$$

are provided in Figure 5. Here $D_{i a}$ is one (zero else) if individual $i$ enters an occupational pension at age $a$. From this figure we can clearly see that the probability of entering early retirement (occupational pension) at the ages 55-59 increases by 60 percentage points on average, or an increase of around 600 percent. The variation in labor supply due to the 1992 Defense Bill is thus what we expected.

Since the number of days is a count variable, it is restricted to be positive and it is also right-skewed. The mean is thus restricted to be positive, and for this reason we use the canonical link function for a Poisson regression model in our main specification when analyzing the effects on health. In the following equation, $H D_{i a}$ denotes days in inpatient care of individual $i$ at age $a$. The implication is that we estimate log linear models, i.e.:

$$
\ln E\left(H D_{i a} \mid M_{i}, C_{i}\right)=\alpha_{0}+\alpha_{1} C_{i 38-39} M_{i}+\alpha_{2} C_{i 38-39}+\alpha_{3} M_{i}
$$

The identifying assumption is that the model should be additive separable at the log level. ${ }^{15}$

\footnotetext{
${ }^{15}$ We have also, as a robustness test, estimated linear regression models; the results are not sensitive to the model specification.
} 
Before turning to the analysis, we first provide an informal test for the identifying assumption of parallel trends in health - in the absence of the Defense Bill - for the military personnel and other government employees at 56-70 years of age.

Unfortunately due to data restrictions we cannot study the evolvement of health at 56-70 years of age before the 1992 Defense bill. The first cohort that we observe in our data is those born in 1931. We have data on inpatient care from 1987. The implication is that we have data on inpatient care from the age of 56 for the 1931 cohort. We have basically two unaffected cohorts, those born 1931 and 1932 (the Bill was taken in February 1992, which means that the birth cohort 1933 may also have been affected) for which we can measure health using inpatient care data at ages 56-60 in the years 1991 and 1992.

We have however, the possibility to study the evolvement of days in inpatient care for individuals in the age span 50-54 years of age from 1987 and onwards. Under the assumption that the health in the age groups 50-54 is proportional and constant over the study period to the health in age span 56-70 for both groups of civil servants, a graph of days in inpatient care at ages 50-54 for the two groups over the study period will provide an informal test of the identifying assumption. The advantage with such an informal test, in contrast to a more traditional difference-in-difference before reform test, is that we can study the evolvement for the two groups (1) in the pre reform period for the same cohorts as being used in the estimation and (2) under the study period, however for other cohorts. The drawback is that we do not study the trends of same outcome as in the main analysis.

In order to provide an understanding for the informal test we show the (predicted) log average number of days in inpatient care at ages 56-60 in the period 1987 to 1999 in Figure 6. From this figure one can see a decreasing trend for both groups. One can potentially also see that the trends for the two groups are similar and that the level of inpatient care is the same or higher for the military personnel before 1994 and lower from 1994 and onwards. In 1994 the 1934 cohort is affected by a maximum of two years of potential early retirement while the 1938 and 1939 cohorts have had a maximum of 5 years of potential early retirement in 1998 and 1999.

Figure 6 consists of real data for the 1993-1999 period but of predicted values for the 1987-1992 period. Figure 7 displays the raw data of log average number of days inpatient care at ages 50-54 over the same period. These data forms the base for the 
informal test and for the predictions made in the 1987-1992 period. ${ }^{16}$ Figure 7 shows a decreasing trend for both groups of civil servants. Based on regression analysis we cannot reject that the trends of the two groups are parallel (p-value of different slopes is slopes is 0.6097) ${ }^{17}$ Hence, this informal test provides no support for rejecting parallel trends in health for the two groups of civil servants after the age of 54, in absence of the 1992 Defense Bill.

Given the extent of studies examining the effects of unemployment on health, the main reason for studying the effect of timing of early retirement on health is that it potentially measures something other than the effect of unemployment on health. One such important difference is that in contrast to being unemployed there should be small or non-existent effects on income of early retirement. For this reason we examine the effects on disposable income for the studied cohorts of military and other civil servants.

Figure 8 shows ordinary least squares (OLS) estimates of $\alpha_{1 a}, a=59,60,61, \ldots, 70$ from the estimation of:

$$
\text { Income }_{i a}=\alpha_{0 a}+\alpha_{1 a} C_{i 38-39} M_{i}+\alpha_{2 a} C_{i 38-39}+\alpha_{3 a} M_{i}+\varepsilon_{i a,} \quad a=59, \ldots, 70,
$$

where Income $_{i a}$ is disposable income of individual $i$ at age $a .{ }^{18}$ The estimates of $\alpha_{1 a}$ are thus the difference-in-difference estimates for each age from 59-70 years of age. From this figure we can see some reform effects on disposable income in ages 59 through 61 . However, the effects are relatively small. We find a statistically significant reduction in disposable income, by 20,000 SEK (2,324 Euro) at ages 59-60 and 10,000 SEK (1,162 Euro) at age 61 . These represent a reduction by about 10 and 5 percent, respectively. At all other ages there is no effect on disposable income. The early retirement program studied here left the retirement income value at normal retirement age unchanged, given that the individual had a full record of 30 years of service. Therefore the long-run effects on income are negligible. All things considered, we conclude that the potential income effects on health are small.

\footnotetext{
${ }^{16}$ To predict days in inpatient care visit at ages 56-60 we multiply days in inpatient care at age 50-54 in 1987 to 1992 with the fraction of inpatient care days at ages 56-60 (cohorts 1931-1932) to that at ages 50-54 (cohorts 1939-1940) in the period 1991-1992.

${ }^{17}$ The p-value for a test of different slopes is 0.5375 for the age group 45-49 years of age. We also estimated second-order polynomial regressions models and tested for differences in gradients between the two groups, but we could not reject the null of equal gradient (results are available upon request).

${ }^{18}$ Note that we have data on disposable income from 1990 and onwards. As a consequence, the age span for model (4) is restricted to starting from age 59, since the oldest birth cohort (born 1931) was 59 years old in 1990.
} 


\subsection{The effect on inpatient care}

The analysis of the effects on the number of days in inpatient care is based on the log linear specification shown in (3). The parameters are estimated using a pseudomaximum-likelihood estimator (using the Poisson distribution in the maximization). The standard errors are estimated using the robust covariance matrix (or the sandwich estimator) and are hence robust to overdispersion. The geographic location of military employees differs from that of other government employees. As there could potentially be different business cycles across regions and regional differences in health care which both could affect health we control for the residential county of the employees when they are 54 years old. In addition we control for labor income at age 54 and education level in a separate regression.

The result from the estimation is displayed in Table 3. The results without controls are provided in columns (1), (3) and (5), while columns (2), (4) and (6) provide results when we add control variables. The results when estimating the effects over the age span 56-70 are presented in columns (1) and (3). In order to study if the effect stems mainly from the first 5 years (when the comparison group is mainly working) or if the effect is more long lasting, we also present results in columns (3)-(6) where the number of days in inpatient care is measured at ages 56-60 and 61-70, respectively.

We find that the number of days in inpatient care for ages 56-70 is reduced by approximately 35 percent on average, due to the opportunity for early retirement. Translating this percentage into the average number of days, the Bill reduced inpatient care days by 6.7 days for ages $56-70 .{ }^{19}$ We can also see that the results are quite robust to the inclusion of control variables.

The results in columns (4) and (6) for the age spans 56-60 and 61-70 (which include controls) respectively, indicate that the point-estimates of the reform effects are almost the same as in age group 56-70 (about 35 percent reduction in comparison to the control group), but that the estimate is less precise for the outcome restricted to the age span 56-60. The effect is statistically significant when measuring outcomes at ages 61-70. Translating this percentage into the average number of days in inpatient care, the reform reduced inpatient care by 2.0 days and 4.7 days in the age spans $56-60$ and 61-70 respectively.

\footnotetext{
${ }^{19}$ That is, $0.35^{*} 19.19=6.7$ days, where 19.19 denotes the weighted averages for number of days in the sample (see Table 2).
} 


\subsubsection{Pooling birth cohorts}

Until now, we have focused our analysis on cohorts that are not affected (i.e., born 1931-1932) and cohorts that are most affected by the 1992 Bill (i.e., born 1938-1939). However, the "middle" cohorts (born 1934-1937) are affected somewhat by the reform (that is, they were given the early retirement offer later than age 55 , but before age 60 ). Hence, these "middle" cohorts may also contribute to a pooled estimation of the reform effect. Pooling birth cohorts should increase the precision of the reform estimate. One way to pool birth cohorts is to estimate the following model:

$$
\ln \left(E\left(H D_{i a} \mid M_{i}, C_{i}, Z_{i}\right)\right)=\alpha_{0}+\alpha_{1} Z_{i} * M_{i}+\sum_{j} \alpha_{2 j} I\left(C_{i}=j\right)+\alpha_{3} M_{i}+\beta X_{i},
$$

where $j$ denotes cohort and $Z_{i}$ is $0,0,0,1,2,3,4,5$, and 5 for the cohorts born 1931, 1932, 1933, 1934, 1935, 1936, 1937, 1938, and 1939. Thus we assume that the reform affected each cohort equal to the number of years the cohort was affected by the 1992 Defense Bill (see Table 1). Military employees born in 1933 are assumed not to be affected by the reform. In this case $\alpha_{1}$ is the average effect on days in inpatient care if the early retirement offer was increased by an additional year of early retirement. We also estimate:

$$
\begin{array}{r}
\ln \left(E\left(H D_{i a} \mid M_{i}, C_{i}\right)\right)=\alpha_{0}+\alpha_{1} I\left(1934 \leq C_{i} \leq 1939\right) * M_{i}+\sum_{j} \alpha_{2 j} I\left(C_{i}=j\right) \\
+\alpha_{3} M_{i}+\beta X_{i}
\end{array}
$$

In this case $\alpha_{1}$ is the pooled effect averaged for all treated cohorts within the range 1934-1939. Finally, we estimate a fully flexible specification:

$$
\ln \left(E\left(H D_{i a} \mid M_{i}, C_{i}\right)\right)=\alpha_{0}+\sum_{j} \alpha_{1 j} I\left(C_{i}=j\right) * M_{i}+\sum_{j} \alpha_{2 j} I\left(C_{i}=j\right)+\beta X_{i}
$$

In this case, the parameters $\alpha_{1 j}(j=1931, \ldots, 1939)$ are separate reform effects for each cohort. This includes no pooling over cohorts.

Table 6 shows the results for the number of days in inpatient care during the period of 56 to 70 years of age. All models include controls for cohort, income, education, and county, in a very flexible manner. From columns (1) and (2) we observe that pooling the cohorts increases the precision. The first column shows that an offered additional year of retirement would decrease the number of days in inpatient care by around 8 percent. This estimate is consistent with the base line results, where an offered 5 -year reduction of retirement age (from age 60 to 55) was found to reduce the number of days in inpatient care by about 35 percent (see Table 3 ). The estimate of the effect, 
when we pool the effect over all treated cohorts from 1934-1939, is presented in column (2). From this column we see an overall reduction in the number of days by around 38 percent, which is almost the same as the estimate in the baseline specification in Table 3 .

From column (1) we can see that in comparison with the cohort born 1931 (reference) there is, as expected, no statistically significant effect for the cohort born 1932. Nor do military employees born 1933 display an effect from the reform, which also corresponds to our expectations, given the timing of the reform. There are statistically significant negative effects of increasing amplitude for the cohorts born 1934 to 1939, except for the cohort born 1937.

In the analyses above, we decided not to censor individuals who died during the age span studied (i.e., before the age of 71). If there is a negative health effect of being offered an early retirement, resulting in increased mortality, then this would reduce the number of days in inpatient care. The implication of this procedure - of not censoring individuals at time of death - is such that it would bias our results downwards. That is, our results could simply stem from an increased mortality of those being offered the occupational pension. Hence it is imperative also to study potential effects on mortality.

\subsection{The effect on mortality}

In this section we again turn to cohorts that are not affected (i.e., cohorts born 19311932) and cohorts that are most affected by the 1992 Bill (i.e., cohorts born 1938-1939).

Figure 9 shows Kaplan-Meier estimates of the survival function (including a 95percent confidence interval) by group, depending on cohort and military status. In comparison with the older cohorts, the survival rates are higher for the younger cohorts. There is also an indication that the increase is greater among the military employees in relation to other civil servants. A rough estimate of the double difference yields an increase of about 4 percentage points in the survival rate. Table 5 shows the results from estimated Cox regression models, in the form of hazard ratios. The first thing to note is that the results are robust to the inclusion of control variables. The risk of dying, up to age 70 , is reduced by approximately 26 percent $\left((1-0.7424)^{*} 100\right)$ by the reform. The effect is larger when censoring the survival time at age 66 .

All in all, the results from the Cox regression models suggest that, if anything, the above estimates for the number of days in inpatient care are biased toward zero. 
That is, by not censoring individuals who died within the age span studied, we are potentially underestimating the effect of the early retirement offer on the number of days in inpatient care.

\subsection{Heterogeneous treatment effect}

The question remains if we can identify which factors in the offer of early retirement that protects from health problems. One might, for example, expect health problems related to a hazardous work environment to be reduced, especially since the effect is potentially larger at younger ages, i.e., at ages before the normal retirement age. Another, complementary, hypothesis is that early retirement lowers the risk of stressrelated heart problems among recipients of the offer (e.g., Steptoe \& Kivimäki, 2013). On the other hand, there is no obvious link between working and cancer. There can be an increased risk for cancer in occupations with specific risk exposures, but then the neoplasm (tumor) should not directly be related to early retirement.

Table 6 gives descriptive statistics of the cause of death for eight classifications (and a separate category, "other", which includes all remaining deaths) in our sample, by cohort and by military status. There is some indication that deaths in acute myocardial infarction, ischemic heart diseases, and neoplasms (tumors) are reduced by the reform (simple difference-in-difference estimator gives estimates ranging from -1.0 to -1.7 percentage points for these three diagnoses), while deaths by external causes or stroke are somewhat increased by the reform (simple difference-in-difference estimator in the order of +0.4 percentage points for both).

As can be seen from Table 6, some causes of death are quite infrequent (alcohol, narcotics, mental and behavioral disorders, and stroke), so in order to estimate a competing risk model, we aggregate alcohol and narcotics, and add mental and behavioral disorders to the "other" group. This leaves us with six large groups in the competing risk model: (1) acute myocardial infarction, (2) stroke and ischemic heart diseases, (1) alcohol and narcotics, (3) external causes, (5) neoplasms (tumors), and (6) other. Estimated results from the competing risk model are presented in Table 7.

From this table, we can see that the risk of dying of acute myocardial infarction, up to the age of 65 , is reduced substantially by the reform. The effect is robust when we include additional controls. There is no other statistically significant cause of death before age 65 . Nor can we find any single cause that is statistically significant up to 
age $70 .^{20}$ In order to study heterogeneous treatment effects further, we estimate effects on the number of days in inpatient care, subdivided into different diagnoses in the next section.

\subsubsection{Effects on number of days in inpatient care due to different diagnoses}

Table 8 provides the results from the estimation of the effect of the offer on the number of days in inpatient care for six diagnosis groups (mental and behavioral disorders, injuries and poisoning, acute myocardial infarction, other ischemic heart diseases, stroke and tumors, and the remaining (other). There is no statistically significant effect on acute myocardial infarction or other ischemic heart diseases. One potential problem or concern regarding the interpretation of this result is the above-observed reduced mortality in these diseases. The implication is that an effect on the number of days in inpatient care could be biased towards zero (or even be positive). There is, however a large reduction in the number of days in inpatient care due to external causes (e.g. injuries and poisoning), by 76-89 percent (see columns (a) and (b)). This indicates that some of the effect stems from less exposure to risks related to the work environment. However, with the full set of controls included in the regression model (see column (c)), the only effect that remains statistically significant is the estimate for diagnosis group "other". We tried to single out a specific diagnosis from this group, without any success. Thus, all things considered, we cannot disentangle a single cause from the collective causes that make up the effect on this morbidity outcome. The main problem is that the occurrence of single diagnoses is a rare event (see column $\mathrm{d}$ ), which influences the power of the tests.

\subsubsection{Heterogeneity in effects depending on pre-retirement income and education}

One other question is whether the reform effect differs across individuals by education and pre-retirement income. The income loss from accepting the offer, in absolute values, is lower for those with low pre-retirement incomes. If there is only a small negative effect of reduced income on health, the positive effect on health could thus

\footnotetext{
${ }^{20}$ The assumption made in the competing risk model is that, conditional on the observed covariates, the risks between the 6 causes of death should be independent. This assumption may be too restrictive, as unobserved health may jointly affect all exits. We tried estimating mixed proportional hazards models (that is, we allowed for unobserved heterogeneity). However, we did not obtain convergence in these models.
} 
be larger for those with low incomes. Another reason for a larger relative health effect among the low-educated and those with low income, is that their work environments and/or their health may be worse than those of high-educated/high-income individuals. This potentially larger effect may be from the instant larger risk reduction, but it is more likely to stem from overall poorer health of the low-educated at the time of being offered retirement. That is, we have the context of a Grossman model in our minds (Grossman 1971). Individuals with low education (low income) have had a more physically demanding working career than those with high education (high income), and consequently their health has deteriorated faster than that of the highly educated. So, at age 55, low-educated individuals' health is worse than the health of those with a higher level of education. However, this effect could also go in the other direction. The reasoning for this is that individuals with a higher education and higher income may value leisure more than individuals with less income and fewer outside options. That is, increasing leisure time may increase life-satisfaction more for those with high education, compared to those with less education, and thus better preserve the health status of individuals with high education, and resulting in more positive health effects for individuals with higher education.

In order to study whether there are any observed differences in effects, we parameterized the intent-to-treat-model to be heterogeneous in both pre-retirement income and education. ${ }^{21}$ For the model that we allow to be heterogeneous with respect to income, we assume the treatment effect to be linear in pre-retirement income; that is, we specify the model as:

$$
\begin{aligned}
\ln E\left(H D_{i a} \mid C_{i 38-39}, \text { inc }_{54}, \text { educ }_{i}\right)= & \alpha_{0}+\alpha_{01} C_{i 38-39} M_{i}+\alpha_{02} C_{i 38-39} M_{i} i n c 54_{i} \\
& +\alpha_{1} i n c 54_{i}+\alpha_{2} C_{i 38-39}+\alpha_{3} M_{i}+\alpha_{4} e d u c_{i},
\end{aligned}
$$

where $i n c 54_{i}$ is annual labor income at age 54 , adjusted for prices and $e d u c_{i}$ is 1 ( 0 else) if the individual has a college education. For the model that we allow for heterogeneous effects from education we instead specify:

$$
\begin{aligned}
\ln E\left(H D_{i a} \mid C_{i 38-39},{\text { inc } \left.54_{i}, e d u c_{i}\right)=}\right. & \alpha_{0}+\alpha_{01} C_{i 38-39} M_{i}+\alpha_{02} C_{i 38-39} M_{i} e d u c_{i} \\
& +\alpha_{1} i n c 54_{i}+\alpha_{2} C_{i 38-39}+\alpha_{3} M_{i}+\alpha_{4} e d u c_{i} .
\end{aligned}
$$

\footnotetext{
${ }^{21}$ We have also estimated models where we have stratified on income and education respectively. The problem with these estimations is the small sample sizes, which are why the precision is too low. The precision in the following non-saturated models enables testing for differences in effects across income and education.
} 
The heterogeneous effect thus equals $\Delta_{i}(x)=\alpha_{01}+\alpha_{02} x_{i}$, where $x$ is either inc54 or educ.

The results from the income and education heterogeneity analysis are shown in columns (1) and (2) respectively of Table 9 . These results indicate that the reform effect is much stronger for low pre-retirement income employees compared to employees with high income before retirement (i.e., at age 54). In Table 9 the effect is evaluated at three income levels: the $25^{\text {th }}$ percentile, mean, and the $75^{\text {th }}$ percentile $(231,000$ SEK $(26,837$ Euro), 295,000 SEK (34,273 Euro), and 335,000 SEK (38,920 Euro), respectively, all in the 2013 price level). The reform resulted in an effect on the number of days in inpatient care which is approximately 20 percentage points (or 50 percent) larger for individuals with a pre-retirement income at the $25^{\text {th }}$ percentile compared to individuals with a pre-retirement income at the $75^{\text {th }}$ percentile.

As for education, the estimate of the reform effect is smaller for those with a college education in comparison to those without. For individuals who did not attend college the retirement offer reduced the number of days in inpatient care by more than 100 percent while it reduced inpatient care days by about 34 percent for individuals with high education ${ }^{22}$

To summarize, this analysis provides evidence of a larger effect of reduced number of inpatient care days for those with low pre-retirement income or with low education. The effects could stem from the larger negative income effect of those with higher income (higher education) or from a more positive effect on health that stems from poorer work environments and/or worse health among those with low income (lower education)

\subsection{Sensitivity analyses using alternative morbidity outcomes}

Based on our detailed register data, we can define an (almost) infinite number of outcome variables. To this end is, thus, the choice of number of days in inpatient care an arbitrary measure of a health outcome. Aside from testing for selective censoring due to death, the analysis of mortality provides a sensitivity analysis for the results obtained using inpatient care outcomes. However, for completeness we also estimated

\footnotetext{
${ }^{22}$ In order to disentangle a potential separate effect from income and education, we specified a model in which both education and income were integrated with the "treatment" and with each other. However, we could not find significant effects with this specification. The problem is that there is not enough variation in the data to separately identify the effects from income and education.
} 
the same type of regressions as with the number of days using the number of episodes (visits that meant inpatient care), and annual prevalence of inpatient care (1 if at least one visit during a year and 0 else) as well.

In all these regressions, receipt of the offer of early retirement decreases both the yearly prevalence of inpatient care and inpatient care visits, and all the estimates are robust to the inclusion of control variables. ${ }^{23}$ These results therefore confirm the previous results, using the number of days in inpatient care only.

\section{The effects of retirement on health}

Earlier studies - discussed in Section 2 - have focused on the effects of retirement on health. We argued that cross-sectional analyses could be questioned, as individual decisions to retire are most likely influenced by health reasons. That is, the population sector that retires early has worse health overall than the population sector retiring later. In the previous chapter we focused on the effects of the offer (i.e., the intentto-treat estimate). However, for comparison we also provided estimates with regard to the effects of retirement on the number of days in inpatient care, using (1) a crosssectional OLS estimator and (2) a two-stage least squares (2SLS) estimator. For the latter, the interaction term military and cohorts 1938-1939 is used as an instrument for the actual retirement decision. Note that the 2SLS estimator allows us to estimate the effect for the individuals who accept early retirement due to the Bill, what is known as the compliers. Potentially this group of individuals differs in their response to early retirement from the group of always-takers by having less severe health problems and by having better work attachment. The implication is that the 2SLS estimator estimates the local average treatment effect (the LATE) instead of the average treatment effect.

The results from these regressions are displayed in panels A and B in Table 10. The results using OLS (panel A) show that early retirement is positively correlated with the number of inpatient care days. These findings subsequently confirm results obtained in other studies (see Section 2 for references) using, for instance, cross section data together with covariate adjustments in regression models. The results from $2 \mathrm{SLS}^{24}$ clearly show that early retirement decreases the number of days in inpatient care over

\footnotetext{
${ }^{23}$ The results can be obtained from the authors upon request.

${ }^{24}$ The results from the first step regression, already displayed in Figure 5, show that early retirement (occupational pension in ages 55-59) increases by 67 percentage points for the group that was given the early retirement offer compared to other groups $(\mathrm{F}=949.11)$
} 
the 15 years under study (from 56 to 70 years of age) by around 8.5 days. The major part of the reduction occurs at later ages, i.e., between ages 61-70.

\section{Conclusions}

This study contributes to the empirical literature by increasing the understanding of the effects of retirement on health. The analysis makes use of detailed longitudinal data on inpatient care, mortality and labor market outcomes. The estimation exploits a targeted retirement offer during 1992-1994 to military employees 55 years of age or older. Before the offer was made, the normal retirement age for military officers was 60 years of age. We estimate the effect on individuals' health during ages 56-70, after being offered retirement at age 55. The identification strategy is based on cohort variation in the timing of the offer, and by using other civil servants not affected by the early retirement offer, to control for secular trends in schooling, nutrition (i.e., early childhood difference at the cohort level), health care technology, and general period effects.

We show that the reform increased early retirement and decreased labor market work in ages 55-59. Moreover, the reform had only short-run effects on disposable income, which is very different from the literature on the effects of job loss or unemployment (e.g., Eliason \& Storrie, 2009a, 2009b, 2011; Browning \& Heinesen, 2012; Black et al., 2013). ${ }^{25}$ More importantly, we find that the opportunity to retire early had positive effects on health; it decreased the number of days in inpatient care and also reduced mortality. Our result is robust to different specifications and alternative inpatient care outcome measures. The effect on mortality is larger when we censor our data at the age of 66 instead of at age 71, and we also find that the risk of dying in acute myocardial infarction is reduced before age 66. This suggests that some of the effect of early retirement on health is from reduced workplace stress.

When we estimate the effect of retiring for the compliers, we find that the number of days in inpatient care is reduced by around 8 days over the 14 years under study

\footnotetext{
${ }^{25}$ This literature makes use of displaced worker and not unemployment per se. The results from US studies find that the earnings losses of displaced workers are large: up to 25 percent five to six years after the displacement (see Kletzer 1998). Using Norwegian data Huttunen et al (2011 finds that a 31 percent increase in the exits from the labor market for the displaced. The long run effect for those remaining in the labor force is modest however. Seven years after the displacement the income loss is estimated to be 3 percent.
} 
(i.e., from 56 to 70 years of age).

The question is how the results compare with earlier results? There are no other comparable studies using inpatient care data why there is no possibility to compare the magnitude of these effects. Based on our point estimates from the Cox regression we find a yearly reduction in mortality by around 26 percent, which implies a yearly reduction by around 0.36 percentage points and a reduction by around 5.4 percentage points over the 15 years study period. ${ }^{26}$ This may seem to be a quite large effect when comparing with the results from the only known earlier study using Swedish employees (Hult et al. 2010). They could not find an effect of early retirement on mortality using data on male builders born 1920 to 1932. However, in a recent study, also using a quasi-experimental design, Bloemen et al. (2013) found point estimates of the same magnitude as ours. They found no effects for females but a decrease in mortality due to an early retirement offer for male civil servants by 42.3 percent over a 5 -year period or a reduced probability to die within five years by 2.5 percentage points.

Our results indicate a larger negative effect on inpatient care days, both for those with low pre-retirement incomes and for those without college education. Those with low income before retirement (or with low education level) most likely have worse work environments on average and/or less good health, in comparison to others, which means that the improved health is linked to less exposure to workplace hazards, which would result from the immediate risk reduction of the retirement or from an indirect effect via a poorer health at the time of the retirement offer.

Most OECD countries are undertaking measures to prolong the careers of older workers. A natural question concerns the effect that postponing retirement may have on individual well-being and, in particular, on health. Unfavorable (or favorable) effects from retirement timing on post-retirement health not only influence individual health but also directly affect health care costs among retirees. Taking cross-sectional studies as evidence of negative effects of retirement on health, suggests a "win-win" situation for extending retirement age in the population. Our findings suggest that increasing mandatory retirement may not, unfortunately, be a "win-win" situation. Early retirement is instead shown to have positive health effects. The positive income effect for the government will most likely also create negative side-effects in terms of

\footnotetext{
${ }^{26}$ The estimation is based on the upper left panel of Figure 9. From this panel we can see that we have have a survival rate of approxiamtly 0.80 . This yields an aproximatly 1.5 percent yearly hazard. A 26 percent decrease imply an yearly reduction by $0.36\left(=1.5^{*}(1-0.76)\right)$ percentage points and hence a total of 5.4 percentage points over the 15 years period.
} 
increasing costs for health care.

Sweden has obligatory public sickness and disability insurance schemes that, in an international context, are generous, both when it comes to the levels of income replacement and also in the degree of monitoring and screening. Sweden also offers public health care at low fees. Given the Swedish institutions, the positive effect on health, generated by the opportunity to retire early, is large and to some extent surprising. We believe that in countries with less generous institutions for sickness (disability) absence and provision of health care, an offer of early retirement, for the same type of employees, would produce a greater effect. 


\section{References}

[1] Black, S. E., Devereux, P. J. \& Salvanes, K. G. (2013). Losing heart? The effect of job displacement on health. NBER Working Paper 18660.

[2] Bloemen, H., Hochguertel, S. \& Zweerink, J. (2013). The causal effect of retirement on mortality: Evidence from targeted incentives to retire early. IZA Discussion Paper 7570 .

[3] Bound, J. \& Waidmann, T. (2008). Estimating the health effects of retirement. University of Michigan Retirement Research Center Working Paper, July 2008.

[4] Browning, M. \& Heinesen, E. (2012). Effect of job loss due to plant closure on mortality and hospitalization. Journal of Health Economics, 31, 599-616.

[5] Charles, K. K. (2002) Is retirement depressing? Labor force inactivity and psychological well-being in later life. NBER Working Paper 9033.

[6] Coe N. B. \& Zamarro, G. (2011) Retirement effect on health in Europe. Journal of Health Economics, 30, 77-86.

[7] Coe N. B. \& Lidboom, M (2008). Does retirement kill you? Evidence from early retirement windows. IZA Discussion Paper 3817.

[8] Eliason, M. \& Storrie, D. (2009a). Does job loss shorten life? Journal of Human Resources, 44, 277-302.

[9] Eliason, M. \& Storrie, D. (2009b). Job loss is bad for your health - Swedish evidence on cause-specific hospitalization following involuntary job loss. Social Science $\mathscr{E}$ Medicine, 68, 1396-1406.

[10] Eliason, M. (2011). Income after job loss: the role of the family and the welfare state. Applied Economics, 2011 (43), 603-618.

[11] Försäkringskassan (2012). Socialförsäkringsrapport 2012:6.

[12] Grossman, M. (1972). On the concept of health capital and the demand for health. Journal of Political Economy, 80, 223-255.

[13] Hernaes, E., Markussen, S., Piggott, J. \& Vestad, O. (2012). Does retirement age impact mortality? CEPAR ARC Working Paper 18. 
[14] Hult, C., Stattin, M., Janlert, U. \& and Järvholm, B. (2010) Timing of retirement and mortality: A cohort study of Swedish construction workers. Social Science in Medicine, 70, 1480-1486.

[15] Huttunen, K., Moen, J. \& Salvanes, K. G. (2011). How destructive is creative destruction? Effects of job loss on job mobility, withdrawal and income. Journal of the European Economic Association, 9, 840-870.

[16] Kletzer, L. G. (1998). Job Displacement. Journal of Economic Perspective, 12, $115-136$.

[17] Kuhn, A., Wuellrich, J. P. \& Zweimüller, J. (2010). Fatal attraction? Access to early retirement and mortality. IZA Discussion Paper 5160.

[18] Neuman, K. (2007). Quit your job and get healthier? The effect of retirement on health. Journal of Labor Research, 29, 177-201.

[19] Prop. 1986/87:95. Försvarsbeslut 1986.

[20] Prop. 1991/92:102. Försvarsbeslut 1992.

[21] SOU (1991:87) Yrkesofficerarnas pensionsålder och åldersstruktur: betänkande av Militära pensionsåldersutredningen. ISBN 91-38-10890-9. Stockholm: Allmänna förl., 1991. Statens offentliga utredningar. (in Swedish)

[22] Steptoe, A. \& Kivimäki, M. (2013). Stress and cardiovascular disease: An update on current knowledge. Annual Review of Public Health, 34, 337-345.

[23] Swedish Association of Local Authorities and Regions. (2005). The Swedish health care system in an international context: A comparison of care needs, costs, and outcomes. http://www.skl.se/MediaBinaryLoader.axd? MediaArchive FileID $=6 b 25$ ef48-5afa-43a4-9800-911324bc42f3

[24] Vahtera, J, Westerlund, H., Hall, M., Sjösten, N., Kivimäki, M., Salo, P., Ferrie, J. E., Jokela, M., Pentti, J., Singh-Manoux, A., Goldberg, M. \& Zins, M. (2009). Effect of retirement on sleep disturbances: The GAZEL prospective cohort study. Sleep, 32, 1459-1466.

[25] Westerlund, H., Kivimäki, M., Singh-Manoux, A., Melchior, M., Ferrie, J. E., Pentti, J., Jokela, M., Leineweber, C., Goldberg, M., Zins, M. \& Vahtera, J. 
(2009) Self-rated health before and after retirement in France (GAZEL): A cohort study. Lancet, 2099, 1889-96.

[26] Westerlund, H., Vahtera, J., Ferrie, J. E., Singh-Manoux, A., Pentti, J., Melchior, M., Leineweber, C., Jokela, M., Siegrist, J., Goldberg, M., Zins, M. \& Kivimäki, M (2010). Effect of retirement on major chronic conditions and fatigue: French GAZEL occupational cohort study. British Medical Journal, 341, c6149.

[27] Victora, C. G, Adair, L., Fall, C., Hallal, P. C., Martorell, R., Richter, L. \& Sachdev, H. S. (2008). Maternal and child undernutrition: Consequences for adult health and human capital. Maternal and Child Undernutrition Study Group, Lancet, 371, 340-57. 


\section{Appendix: Swedish institutions}

\section{The pension system}

The Swedish public pension system was reformed in 1998. The 1938 cohort was the first to receive old-age pensions from the new scheme, with 4/20 of their pension benefits coming from the new scheme and 16/20 coming from the old scheme. Each successive cohort receives an additional 1/20 from the new scheme and 1/20 less from the old scheme (the cohorts born 1954 or later receive their pensions only from the new scheme). Since there is a cohort-based element that slowly phases in the new pension scheme, individuals born 1938-1953 are in both the new and the old schemes. Thus the cohorts studied here - born 1931 to 1939 - receive public pensions mainly from the former system.

The former old-age public pension system was a defined benefit scheme consisting of a flat-rate basic pension and an income-related supplementary pension based on the best 15 out of 30 years of earnings. ${ }^{27}$ The new system is a combination of notional defined contributions on a pay-as-you-go basis, which is based on pension contributions to income throughout the whole working career, rather than just the 15 best years, and a smaller defined contribution scheme in which the contributions are invested in mutual funds or bonds. Individuals with small or no pension claims receive a guaranteed pension. The old system had a normal pension age of 65 but in the new system the retirement age is flexible. The main factor determining replacement rates in the old system was the age at retirement in relation to the normal pension age of 65 , through actuarial adjustments. The replacement rate in the new system is instead determined by a cohort-specific devisor that is governed by life expectancy at age 65 , and periodspecific indexation that may slow down or speed up the development of pension benefits in relation to wages, depending on the financial situation in the pension system as a whole.

The current public pension system has a cap at 424,500 SEK in 2013 prices (about 49,000 Euro). During the time period of studied in this paper the old public pension system operated, and the cap was 333,750 SEK in 2013 prices (about 38,000 Euro). For most employees, incomes above the cap are covered by occupational pension schemes, which are supplemental pensions arising from collective agreements made by the unions and employers' federations.

\footnotetext{
${ }^{27}$ For those with less than 30 years of service the benefit was reduced proportionally.
} 


\section{Social insurances}

All workers (employed and unemployed) are covered by the public sickness and disability insurance schemes. Most workers are also covered by an unemployment insurance scheme. Unemployed individuals (either covered or not covered by the unemployment insurance scheme) have access to the sickness insurance scheme. Until July 2008, there was no formal time restriction on the length of sick leave under the sickness insurance scheme. Such formal time restrictions do exist in the unemployment insurance scheme, however. Overall, the benefit requirements are the least generous in the unemployment insurance scheme and the most generous in the sickness insurance scheme.

During the first seven days of sick leave, it is up to the individual to decide whether or not (s)he is ill and the extent to which this warrants absence from work. The individual merely has to inform the employer that he or she is ill. As of the eighth day, a medical certificate is required. For sick leave continuing longer than two weeks, the employer notifies the Sickness Insurance Agency (SIA) about continuation. The SIA sends a letter to the insured person with a form and a request for a medical certificate. In the certificate, the doctor indicates the length and extent of sick leave that (s)he believes is necessary. Based on the medical certificate, the SIA determines the right to sick leave, a process that normally takes at least one to two weeks after the end of the sick-leave period paid for by the employer. When this first sick-leave period with benefits from the SIA has expired, a renewal certificate is issued if required. The renewal certificate is also sent to the SIA and a new assessment of the right to sickness benefits is made. When the renewal certificate expires and if the insured person is still sick, the process is repeated.

\section{Health care}

The local county councils are the major financiers and providers of Swedish health care. There are 25 county councils and each council is obliged to provide its residents with equal access to health services and medical care. Health care is mostly financed through local taxes. Each county council sets its own patient fees, but a national ceiling limits the total amount that a patient pays during a 12-month period (out-of-pocket). Thus, patient fees only account for about 3 percent of the total revenue. The daily fee for staying at a hospital is about USD 15. There is free choice of provider but referral is required in some cases, particularly when patients seek specialized care, or when they choose health care in another county. The county councils are allowed to contract 
private providers, but the majority of the health care is performed by public agents. ${ }^{28}$

\footnotetext{
${ }^{28}$ For more details of the Swedish health care system see the Swedish Association of Local Authorities and Regions (2005).
} 
Table 1: Age groups and birth cohorts that were affected by the defense bill in 1992 (age as measured by December 31)

\begin{tabular}{|c|c|c|c|c|c|}
\hline \multirow[t]{2}{*}{ Birth cohort } & \multicolumn{5}{|c|}{ Ages between 55 and 59 affected by the reform per birth cohor } \\
\hline & 55 & 56 & 57 & 58 & 59 \\
\hline 1931 & 1986 & 1987 & 1988 & 1989 & 1990 \\
\hline 1932 & 1987 & 1988 & 1989 & 1990 & 1991 \\
\hline 1933 & 1988 & 1989 & 1990 & 1991 & 1992 \\
\hline 1934 & 1989 & 1990 & 1991 & 1992 & 1993 \\
\hline 1935 & 1990 & 1991 & 1992 & 1993 & 1994 \\
\hline 1936 & 1991 & 1992 & 1993 & 1994 & 1995 \\
\hline 1937 & 1992 & 1993 & 1994 & 1995 & 1996 \\
\hline 1938 & 1993 & 1994 & 1995 & 1996 & 1997 \\
\hline 1939 & 1994 & 1995 & 1996 & 1997 & 1998 \\
\hline
\end{tabular}

Note: The defense bill was taken by the parliament in February 1992 and the reform was implemented thereafter in the course of 1992. We view 1992 as an implementation year, which means that it is difficult to pinpoint exactly whether or not those born in 1933 should be regarded as affected by the reform (they turned 59 in 1992). Therefore the year "1992" is shaded in light grey. 
Table 2: Summary statistics for estimation sample, by birth cohort and military status

\begin{tabular}{|c|c|c|c|c|c|c|c|c|}
\hline & \multicolumn{4}{|c|}{ Military } & \multicolumn{4}{|c|}{ Non-military } \\
\hline & \multicolumn{2}{|c|}{$1931-1932$} & \multicolumn{2}{|c|}{$1938-1939$} & \multicolumn{2}{|c|}{ 1931-1932 } & \multicolumn{2}{|c|}{$1938-1939$} \\
\hline & Mean & SD & Mean & SD & Mean & SD & Mean & SD \\
\hline $\begin{array}{l}\text { Labor income at age } 54 / 1000 \\
\text { (SEK) }\end{array}$ & 288.8 & 74.8 & 383.8 & 134.0 & 272.5 & 99.9 & 319.4 & 129.3 \\
\hline $\begin{array}{l}1 \text { If labor income at age } 54 \text { above } \\
\text { cap }\end{array}$ & 0.23 & & 0.55 & & 0.18 & & 0.33 & \\
\hline $\begin{array}{l}\text { Disposable income at age } 59 / 1000 \\
\text { (SEK) }\end{array}$ & 235.4 & 62.1 & 226.2 & 87.0 & 217.5 & 78.9 & 231.4 & 130.5 \\
\hline $\begin{array}{l}1 \text { If occupational pension at age } \\
54\end{array}$ & 0.00 & & 0.01 & & 0.00 & & 0.01 & \\
\hline $\begin{array}{l}1 \text { If occupational pension at ages } \\
55-59\end{array}$ & 0.09 & & 0.78 & & 0.10 & & 0.18 & \\
\hline $\begin{array}{l}1 \text { If labor income }>1 \text { PBA at ages } \\
56-60\end{array}$ & 0.99 & & 0.62 & & 0.98 & & 0.96 & \\
\hline $\begin{array}{l}1 \text { If gainfully employed at age } 55 \\
\text { to } 59\end{array}$ & 0.98 & & 0.84 & & 0.98 & & 0.97 & \\
\hline Education level (yrs of schooling) & 14.8 & 0.8 & 14.9 & 0.5 & 12.7 & 3.1 & 12.7 & 3.2 \\
\hline \multicolumn{9}{|l|}{ Number of days in inpatient care } \\
\hline during ages $56-70$ & 24.99 & 91.82 & 11.17 & 22.62 & 21.62 & 58.75 & 15.91 & 39.69 \\
\hline during ages $56-60$ & 8.99 & 66.54 & 2.68 & 9.38 & 7.05 & 40.90 & 4.01 & 17.18 \\
\hline during ages $61-70$ & 16.01 & 38.39 & 8.48 & 19.86 & 14.57 & 36.74 & 11.91 & 32.36 \\
\hline \multicolumn{9}{|l|}{1 if days $>0$} \\
\hline during ages $56-70$ & 0.70 & & 0.65 & & 0.69 & & 0.65 & \\
\hline during ages $56-60$ & 0.33 & & 0.27 & & 0.33 & & 0.29 & \\
\hline during ages $61-70$ & 0.58 & & 0.55 & & 0.58 & & 0.55 & \\
\hline \multicolumn{9}{|c|}{ Number of hospital inpatient episodes (prevalence) } \\
\hline during ages $56-70$ & 3.25 & 4.56 & 2.37 & 3.50 & 3.24 & 5.07 & 2.86 & 4.61 \\
\hline during ages $56-60$ & 0.93 & 2.05 & 0.52 & 1.19 & 0.88 & 2.18 & 0.75 & 1.87 \\
\hline during ages $61-70$ & 2.32 & 3.57 & 1.85 & 3.10 & 2.36 & 4.05 & 2.11 & 3.69 \\
\hline Dead (before age 71) & 0.19 & & 0.12 & & 0.16 & & 0.13 & \\
\hline Number of observations & 59 & & 69 & & & 997 & & 596 \\
\hline
\end{tabular}

Note: Disposable income is measured at age 59 because this is the earliest point in data for all cohorts. Disposable income and labor income are in the 2013 price level, thousands SEK. Income above the cap means income $>7.5^{*}$ PBA, where PBA is 1 Price Base Amount (PBA), which is 44,500 SEK in 2013. Gainful employment is defined according to the ILO definition. Years of schooling is calculated from education level data. 
Table 3: Effects of the early retirement offer on number of days inpatient care

\begin{tabular}{lcccccc}
\hline & \multicolumn{2}{c}{ Ages 56-70 } & \multicolumn{2}{c}{ Ages 56-60 } & \multicolumn{2}{c}{ Ages 61-70 } \\
\hline \multirow{3}{*}{ Effect } & $(1)$ & $(2)$ & $(3)$ & $(4)$ & $(5)$ & $(6)$ \\
& $-0.4989^{* *}$ & $-0.3472^{*}$ & $-0.6424 \dagger$ & -0.3413 & $-0.4331^{* *}$ & $-0.3540^{*}$ \\
\multirow{2}{*}{ Controls } & $(0.1729)$ & $(0.1446)$ & $(0.3383)$ & $(0.2574)$ & $(0.138)$ & $(0.1595)$ \\
& No & Yes & No & Yes & No & Yes \\
\hline
\end{tabular}

Notes: Estimation is performed with the Poisson maximum likelihood estimator. Robust standard errors in (): $\dagger \mathrm{p}<.1$; ${ }^{*} \mathrm{p}<.05 ; * * \mathrm{p}<.01$. Each cell represents estimates from a separate model. All models include a military dummy and dummy for cohort 1938-1939. Control variables are county dummies, income and education, and interaction terms (interactions between military, income, and education, and interactions between cohort, income, and education). The number of observations is 19,986.

Table 4: Effects of the offer to receive occupational pensions on number of days in inpatient care during 56 to 70 years of age: (1) linear, (2) pooled, and (3) by individual cohort (the 1931 birth cohort as reference)

\begin{tabular}{|c|c|c|c|}
\hline & (1) & (2) & (3) \\
\hline$M^{*} Z$ & $\begin{array}{c}-0.0833^{* *} \\
(0.0293)\end{array}$ & & \\
\hline $1934 \leq$ Cohort $\leq 1939$ & & $\begin{array}{c}-0.3755^{\star *} \\
(0.1258)\end{array}$ & \\
\hline 1932 Cohort & & & $\begin{array}{r}-0.3101 \\
(0.262)\end{array}$ \\
\hline 1933 Cohort & & & $\begin{array}{c}-0.1672 \\
(0.2765)\end{array}$ \\
\hline 1934 Cohort & & & $\begin{array}{c}-0.5246 \dagger \\
(0.2753)\end{array}$ \\
\hline 1935 Cohort & & & $\begin{array}{l}-0.5450^{*} \\
(0.2602)\end{array}$ \\
\hline 1936 Cohort & & & $\begin{array}{c}-0.4294 \dagger \\
(0.2576)\end{array}$ \\
\hline 1937 Cohort & & & $\begin{array}{r}-0.3883 \\
(0.266)\end{array}$ \\
\hline 1938 Cohort & & & $\begin{array}{r}-0.6163^{*} \\
(0.258)\end{array}$ \\
\hline 1939 Cohort & & & $\begin{array}{l}-0.6149^{*} \\
(0.2591)\end{array}$ \\
\hline
\end{tabular}

Note. Estimation is performed with the Poisson maximum likelihood estimator. Robust standard errors in (): $\dagger$ $\mathrm{p}<.1{ }^{*} \mathrm{p}<.05$; ** $\mathrm{p}<.01$. Z takes the values $0,0,0,1,2,3,4,5$, and 5 for the cohorts born 1931, 1932, 1933, 1934, 1935, 1936, 1937, 1938, and 1939. All models include controls for military (M), cohort, county, income, and education, and interactions between income and cohort, and education and cohort. The number of observations is 47,038 . 
Table 5: The effect (hazard ratio) of being offered early retirement on the conditional probability of dying, based on a discrete-time Cox regression model

\begin{tabular}{lcccccc}
\hline & \multicolumn{3}{c}{ Censoring at age 71 } & \multicolumn{3}{c}{ Censoring at age 66 } \\
\hline \multirow{3}{*}{ Hazard ratio } & $(1)$ & $(2)$ & $(3)$ & $(4)$ & $(5)$ & $(6)$ \\
& $0.7275^{\star}$ & $0.7242^{*}$ & $0.7424 \dagger$ & $0.5899^{*}$ & $0.5926^{*}$ & $0.6109^{*}$ \\
County & $(0.1107)$ & $(0.1102)$ & $(0.1148)$ & $(0.1215)$ & $(0.1222)$ & $(0.1283)$ \\
Control variables & No & Yes & Yes & No & Yes & Yes \\
& No & No & Yes & No & No & Yes \\
\hline
\end{tabular}

Note. Estimation is performed with maximum likelihood. Standard errors are adjusted for 19, 906 clusters (individuals): $\dagger \mathrm{p}<.1 ; * \mathrm{p}<.05 ; * * \mathrm{p}<.01$. Control variables are income, income interacted with dummy for cohort 1938-1939, and education. All models include a military dummy and dummy for cohort 1938-1939. The number of observations is 283,208 and 232,087 for the estimates that are censored at age 71 and age 66 respectively.

Table 6: Causes of death, ages 55-70, column percentage, by group

\begin{tabular}{lcccc}
\hline & \multicolumn{2}{c}{ Military } & \multicolumn{2}{c}{ Non-military } \\
\hline Cohort & $31-32$ & $38-39$ & $31-32$ & $38-39$ \\
Acute myocardial infarction & 4.5 & 1.6 & 3.0 & 1.8 \\
Ischemic heart diseases & 2.0 & 0.7 & 1.2 & 0.9 \\
Alcohol & 1.2 & 0.9 & 0.5 & 0.5 \\
Narcotics & 0.0 & 0.0 & 0.1 & 0.0 \\
Mental and behavioral disorders & 0.0 & 0.3 & 0.3 & 0.3 \\
External causes & 1.0 & 1.2 & 0.9 & 0.6 \\
Stroke & 0.5 & 0.7 & 0.4 & 0.2 \\
Neoplasms (tumors) & 7.0 & 4.9 & 5.9 & 5.5 \\
Other & 3.0 & 1.6 & 3.5 & 2.9 \\
Total deaths, ages 55-70 & 19.2 & $\mathbf{1 1 . 8}$ & 15.7 & 12.8 \\
Alive at 70 & 80.8 & 88.2 & 84.3 & 87.2 \\
Total & 100.0 & 100.0 & 100.0 & 100.0 \\
Observations & 598 & 695 & 11,097 & 7,596 \\
\hline
\end{tabular}

Note. ICD-codes (International Statistical Classification of Diseases and Related Health Problems) are: Acute myocardial infarction: ICD10 I21-I22, ICD9 410; Ischemic heart diseases except acute myocardial infarction: ICD10 I20, I23-I25, ICD9 411-414; Alcohol: an alcohol-related diagnosis is mentioned among causes of death (as main or contributing diagnosis); Narcotics: a narcotics-related diagnosis is mentioned among causes of death (as main or contributing diagnosis); Mental and behavioral disorders: ICD10 F00-F99, ICD9 290319; External causes of morbidity and mortality: ICD10 V01-Y98, ICD9 E810-E999; Stroke: ICD10 I63-I64, ICD9 433, 434, 435; Neoplasms (tumors): ICD10 C00-D48, ICD9 140-239. 
Table 7: The effect (hazard ratio) of being offered early retirement on the conditional probability of dying, based on a discrete-time Cox regression model, by cause of death

\begin{tabular}{lcccc}
\hline & \multicolumn{2}{c}{ Censoring at 71 } & \multicolumn{2}{c}{ Censoring at 66} \\
\hline Acute myocardial infarction & 0.5889 & 0.5767 & $0.2670^{*}$ & $0.2776^{*}$ \\
& $(0.2189)$ & $(0.2197)$ & $(0.1515)$ & $(0.163)$ \\
Ischemic heart diseases and Stroke & 0.9183 & 0.917 & 0.4994 & 0.4955 \\
& $(0.4065)$ & $(0.4225)$ & $(0.2863)$ & $(0.2964)$ \\
Neoplasms (tumors) & 0.691 & 0.7057 & 0.5796 & 0.586 \\
& $(0.1675)$ & $(0.1708)$ & $(0.1971)$ & $(0.1985)$ \\
Alcohol or narcotics & 0.7851 & 0.8266 & 0.7446 & 0.8054 \\
& $(0.4813)$ & $(0.5377)$ & $(0.5371)$ & $(0.6329)$ \\
External causes & 1.643 & 1.3309 & 2.1868 & 1.7189 \\
Other & $(0.937)$ & $(0.7809)$ & $(1.6744)$ & $(1.3388)$ \\
& 0.6533 & 0.7402 & 0.8499 & 1.0908 \\
Controls & $(0.2489)$ & $(0.287)$ & $(0.4502)$ & $(0.591)$ \\
\hline
\end{tabular}

Note. Estimation is performed with maximum likelihood. Standard errors are adjusted for 19, 906 clusters (individuals): $\dagger \mathrm{p}<.1{ }^{*} \mathrm{p}<.05 ; * * \mathrm{p}<.01$. All models include a military dummy and dummy for cohort 19381939. 'Controls' are income, income interacted with dummy for cohort 1938-1939, and education. The number of observations is 283,208 and 232,087 for the estimates that are censored at age 71 and at age 66 respectively. The exact ICD-codes for groups are given in Table 6. 
Table 8. Effects of the offer to receive occupational pensions on number of days in inpatient care during the period of 56 to 70 years of age: Subdivided into different causes for the visit

\begin{tabular}{lcccc}
\hline & $(\mathbf{a})$ & $\mathbf{( b )}$ & $\mathbf{( c )}$ & $\begin{array}{c}\text { Mean number of } \\
\text { days [SD] }\end{array}$ \\
\hline Acute myocardial infarction & -0.2787 & -0.1865 & -0.1361 & 0.65 [3.30] \\
Ischemic heart diseases & $(0.2498)$ & $(0.2512)$ & $(0.3427)$ & \\
Mental and behavioral disorders & 0.2065 & 0.2848 & 0.2641 & 1.04 [4.71] \\
& $(0.2396)$ & $(0.2389)$ & $(0.2803)$ & \\
External causes (e.g., injury, poisoning) & 0.1805 & 0.6234 & 0.1065 & 1.66 [22.05] \\
& $(0.6562)$ & $(0.6643)$ & $(0.704)$ & \\
Stroke & $(0.3171)$ & $(0.3151)$ & $(0.3881)$ & 1.04 [7.80] \\
Neoplasms (tumors) & -0.4532 & -0.3332 & -0.3714 & 1.11 [9.71] \\
& $(0.5686)$ & $(0.5754)$ & $(0.6913)$ & \\
Other & $-0.4238 \dagger$ & -0.3747 & -0.4095 & 3.68 [16.79] \\
& $(0.2452)$ & $(0.2449)$ & $(0.289)$ & \\
County & $-0.5971^{*}$ & $-0.4421 \dagger$ & $-0.3932^{*}$ & 10.19 [38.33] \\
Income and education & $(0.2565)$ & $(0.2504)$ & $(0.1818)$ & \\
"Full interaction" & No & Yes & Yes & \\
\hline
\end{tabular}

Notes: Estimation is performed with the Poisson maximum likelihood estimator. Robust standard errors in () and standard deviation (SD) in [ ]: $\dagger \mathrm{p}<.1 ;{ }^{*} \mathrm{p}<.05$; ${ }^{*} \mathrm{p}<.01$. Each cell represents estimates from a separate model. All models include a military dummy and dummy for cohort 1938-1939. Control variables are income, education, cohort, and military. "Full interaction" means interactions between military, income, and education, and interactions between cohort, income, and education. Column (d) gives the mean and standard deviation in the number of days per diagnosis group. Number of observations is 19,986. ICD-codes (International Statistical Classification of Diseases and Related Health Problems) are: Acute myocardial infarction: ICD10 I21-I22, ICD9 410; Alcohol: an alcohol-related diagnosis is mentioned among causes of death (as main or contributing diagnosis); Ischemic heart diseases except acute myocardial infarction: ICD10 I20, I23-I25, ICD9 411-414; Narcotics: a narcotics-related diagnosis is mentioned among causes of death (as main or contributing diagnosis); Mental and behavioral disorders: ICD10 F00-F99, ICD9 290-319; Injury, poisoning and certain other consequences of external causes: ICD10 S00-T98, ICD9 E810-E999; Stroke: ICD10 I63-I64, ICD9 433, 434, 435; Neoplasms (tumors): ICD10 C00-D48, ICD9 140-239. 
Table 9: Heterogeneous effects on inpatient care with respect to pre-retirement income (column 1) and education (column 2) during ages 56-70

\begin{tabular}{lcc}
\hline & Income & Education \\
\hline Main effect & $\begin{array}{c}-0.9779^{* *} \\
(0.328)\end{array}$ & $\begin{array}{c}-1.0375^{\star *} \\
(0.3726)\end{array}$ \\
Heterogenous effect with respect to income & $\begin{array}{c}0.0809^{*} \\
(0.0315)\end{array}$ & \\
Heterogenous effect with respect to education & & $0.7022^{*}$ \\
Evaluated at p25 (231,000 SEK; 26,837 Euro) & & $(0.3534)$ \\
Evaluated at mean $(295,000$ SEK; 34,273 Euro) & & - \\
Evaluated at p75 (335,000 SEK; 38,920 Euro) & -0.558 & - \\
Evaluated at educ = 1 (high education, college) & -0.442 & - \\
\hline
\end{tabular}

Note: Estimation is performed with the Poisson maximum likelihood estimator. Robust standard errors in (): $\dagger$ $\mathrm{p}<.1$; $^{*} \mathrm{p}<.05 ;{ }^{* *} \mathrm{p}<.01$. \&The evaluation is based on the specification $\hat{\alpha}_{01}+\hat{\alpha}_{02}$ inc 54 , where inc54 is income at age 54 . \#The evaluation is based on the specification $\hat{\alpha}_{01}+\hat{\alpha}_{02} e d u c$, where educ is 1 if college educated. The number of observations is 19,986. All models control for the main effects, that is, inc54, educ, military dummy and dummy for cohort 1938-1939.

Table 10: Results from regressions (OLS and 2SLS) of number of days in inpatient care on early retirement (prevalence of occupational pensions between the ages 55-59)

\begin{tabular}{lcccccc}
\hline \multicolumn{7}{c}{ A: OLS } \\
\hline \multirow{2}{*}{ Ages 56-70 } & \multicolumn{2}{c}{ Ages 56-60 } & \multicolumn{2}{c}{ Ages 61-70 } \\
& $12.41^{* *}$ & $14.27^{* *}$ & $7.33^{* *}$ & $7.98^{* *}$ & $5.08^{* *}$ & $6.29^{* *}$ \\
& $(1.73)$ & $(1.74)$ & $(1.36)$ & $(1.37)$ & $(0.87)$ & $(0.88)$ \\
Effect & & & B: 2 SLS & & & \\
Controls & $-8.48^{*}$ & $-13.34^{*}$ & -2.57 & -5.35 & $-5.92^{*}$ & $-7.99^{* *}$ \\
& $(3.93)$ & $(6.50)$ & $(2.22)$ & $(4.58)$ & $(2.80)$ & $(3.02)$ \\
& Yes & No & Yes & No & Yes & No \\
\hline
\end{tabular}

Notes: Excluded instrument in the 2SLS estimation is cohort 1938-1939*military. Robust standard errors in ()$: \dagger \mathrm{p}<.1 ; * \mathrm{p}<.05 ; * * \mathrm{p}<.01$. Each cell represents estimates from a separate model. All models include a military dummy and dummy for cohort 1938-1939. Control variables (and interactions) are the same as in Table 3. Number of observations is 19,986 . 

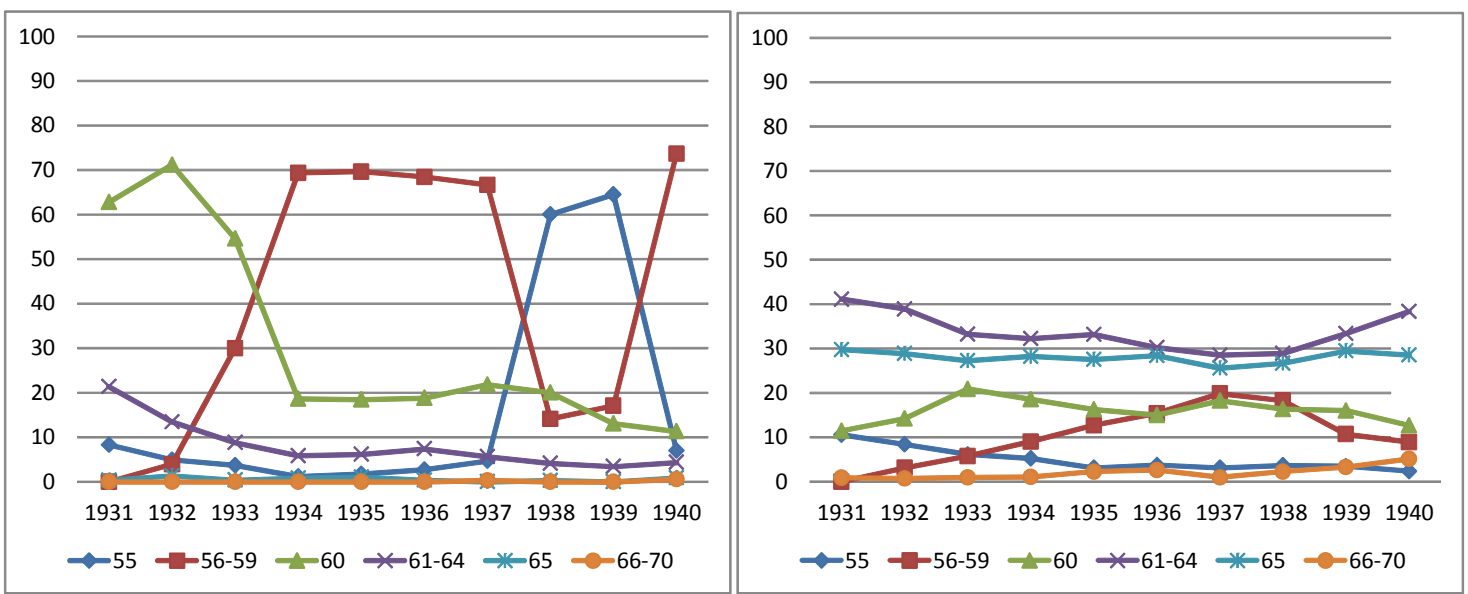

Figure 1: Retirement age (first year with occupational pension take-up) by birth cohort, percent (fractions sum to 100 per birth cohort); birth cohorts 1931-1940; military personnel (left) and other government employees (right).

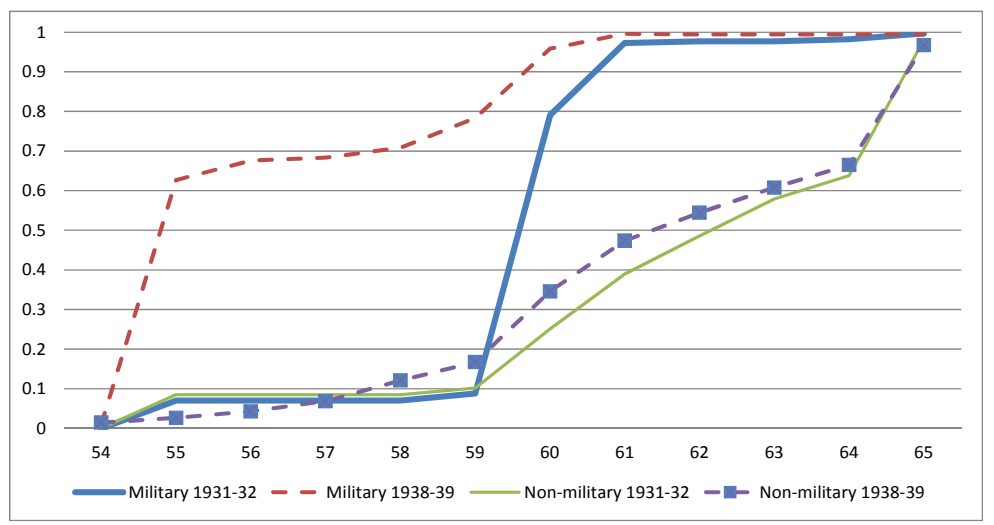

Figure 2: The take-up rate of occupational pension among military and nonmilitary government employees for the two cohorts 1931-1932 and 1938-1939.

Note: For cohort 1931, ages 55-58, and cohort 1932, ages 55-57, the fractions are estimated with the value in 1990 (data on pension income starts in 1990).

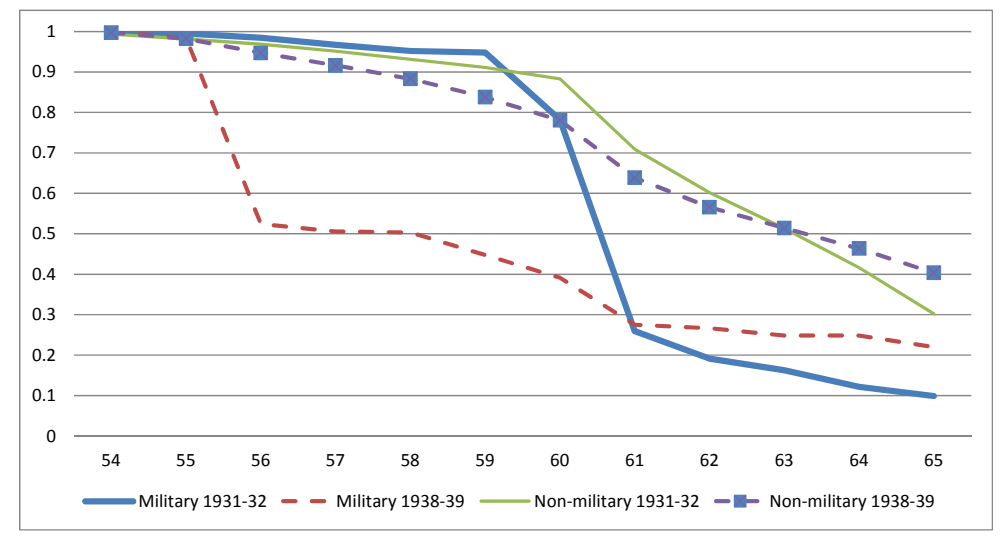

Figure 3: Fraction employed among military and non-military government employees for the two cohorts 1931-1932 and 1938-1939.

Note: Employment status is defined as labor market income above one basic amount in a given year. 


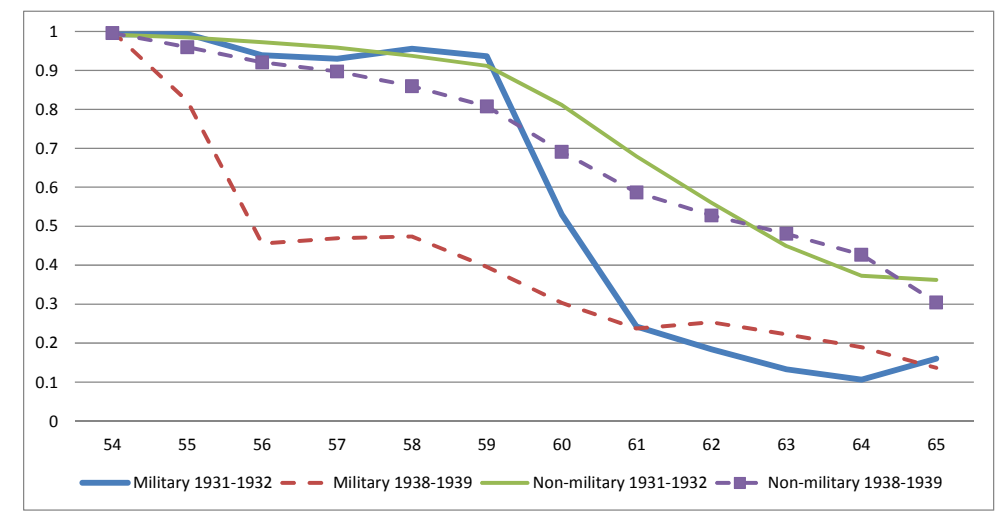

Figure 4: Fraction registered as gainfully employed among military and nonmilitary government employees for the two cohorts 1931-1932 and 1938-1939.

Note: Gainful employment is defined according to the ILO definition, November each year, administrative registers (RAMS, Statistics Sweden).

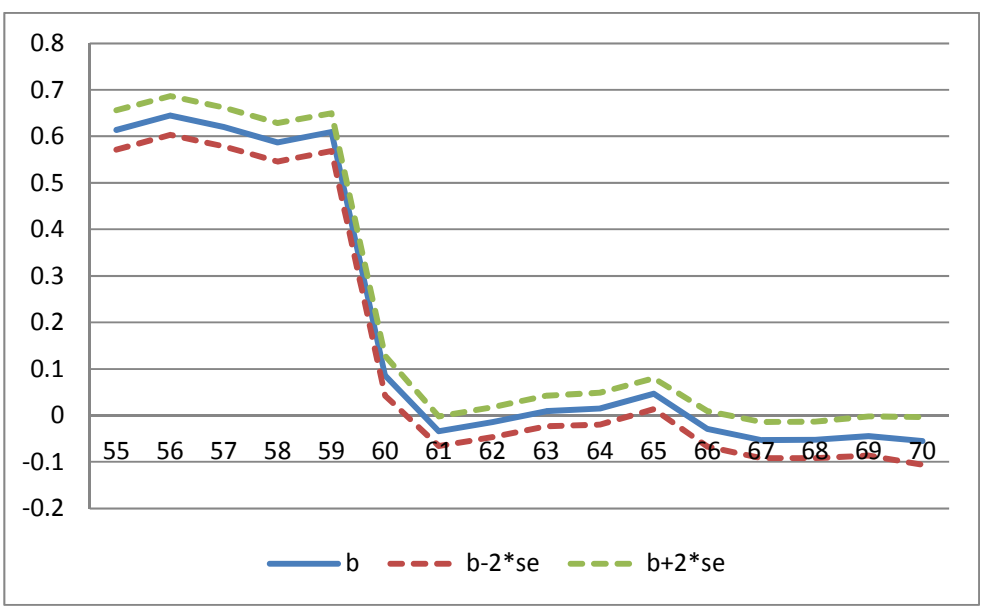

Figure 5: The effect on occupational pension take-up; interaction term in a difference-in-difference-specification; other variables include dummy for military and birth year 1938-1939.

Note: For cohort 1931, ages 55-58, and cohort 1932, age 55-57, the fractions are estimated with the value in 1990 (data on pension incomes starts in 1990). 


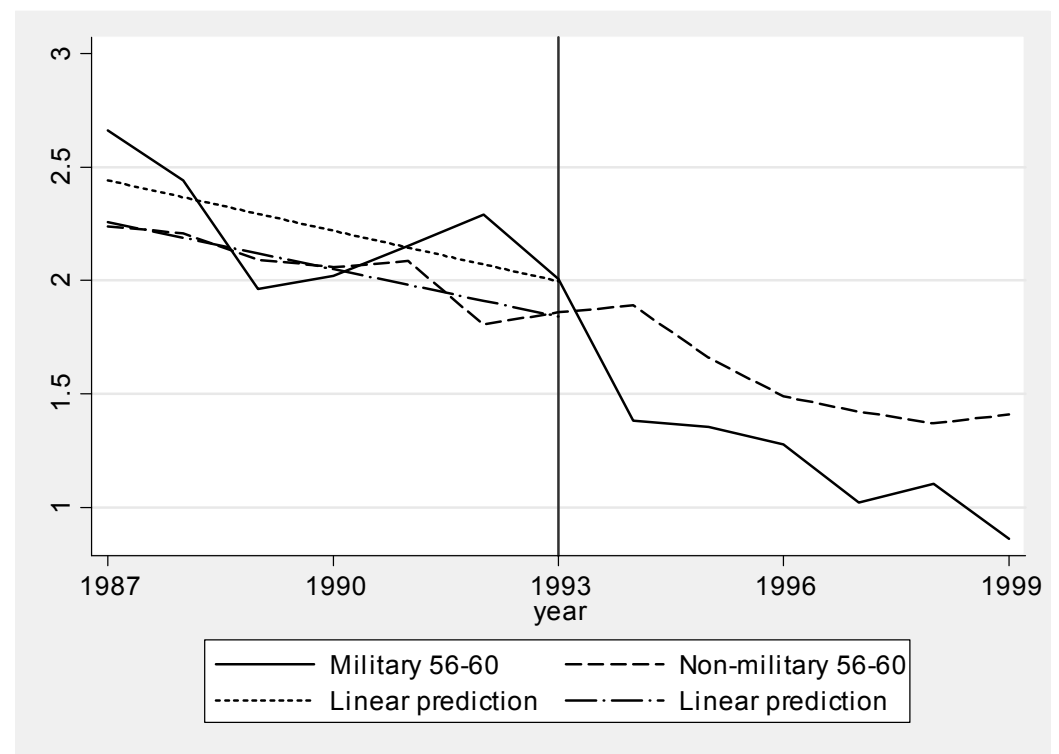

Figure 6: Log average days in inpatient care at 56-60 years of age (based on predicted values for 1987-1992 and real data for 1993-1999) before and after the reform and estimated linear trends 1987-1993; 1987-1999; the estimated slopes of the trend (before 1993) are -0.0742 and -0.0694 for military and non-military, respectively.

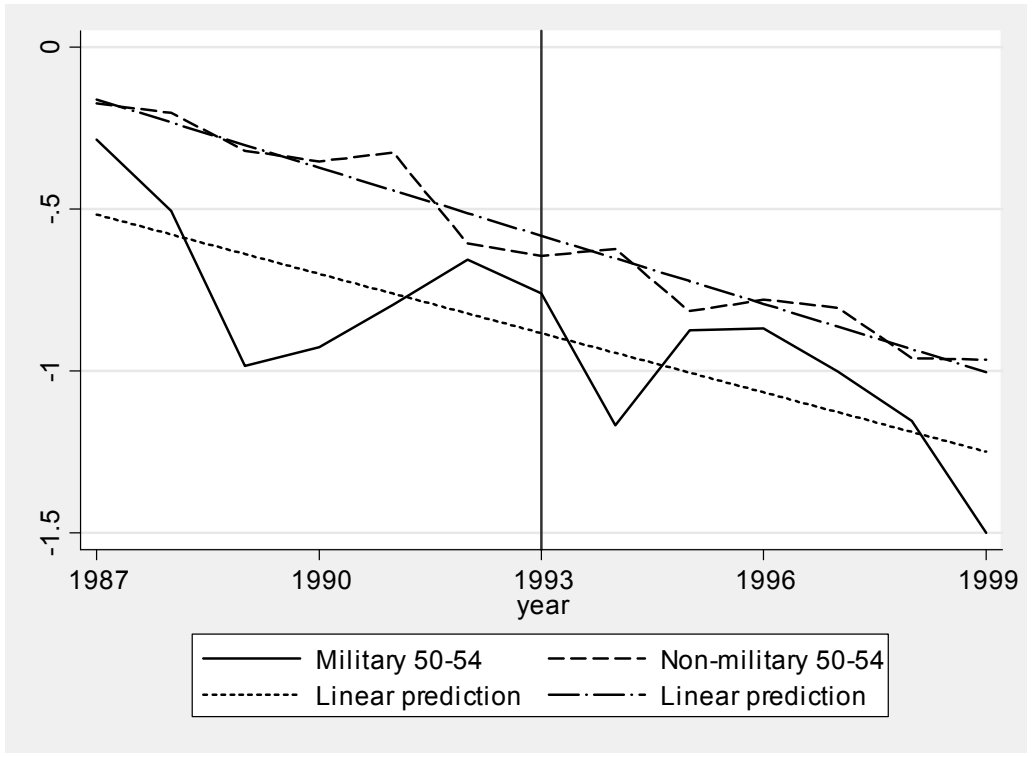

Figure 7: Log average days in inpatient care at 50-54 years of age and estimated linear trends; period 1987-1999; the estimated slopes of the trend are -0.0611 and -0.0701 for military and non-military, respectively. 


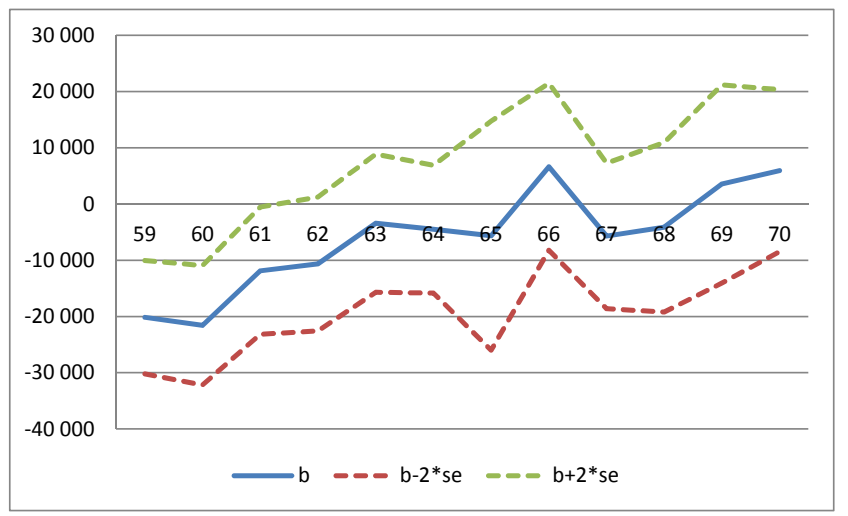

Figure 8: The effect on disposable income (SEK per year); the interaction term in a difference-in-difference specification; other variables include dummy for military and birth year 1938-1939

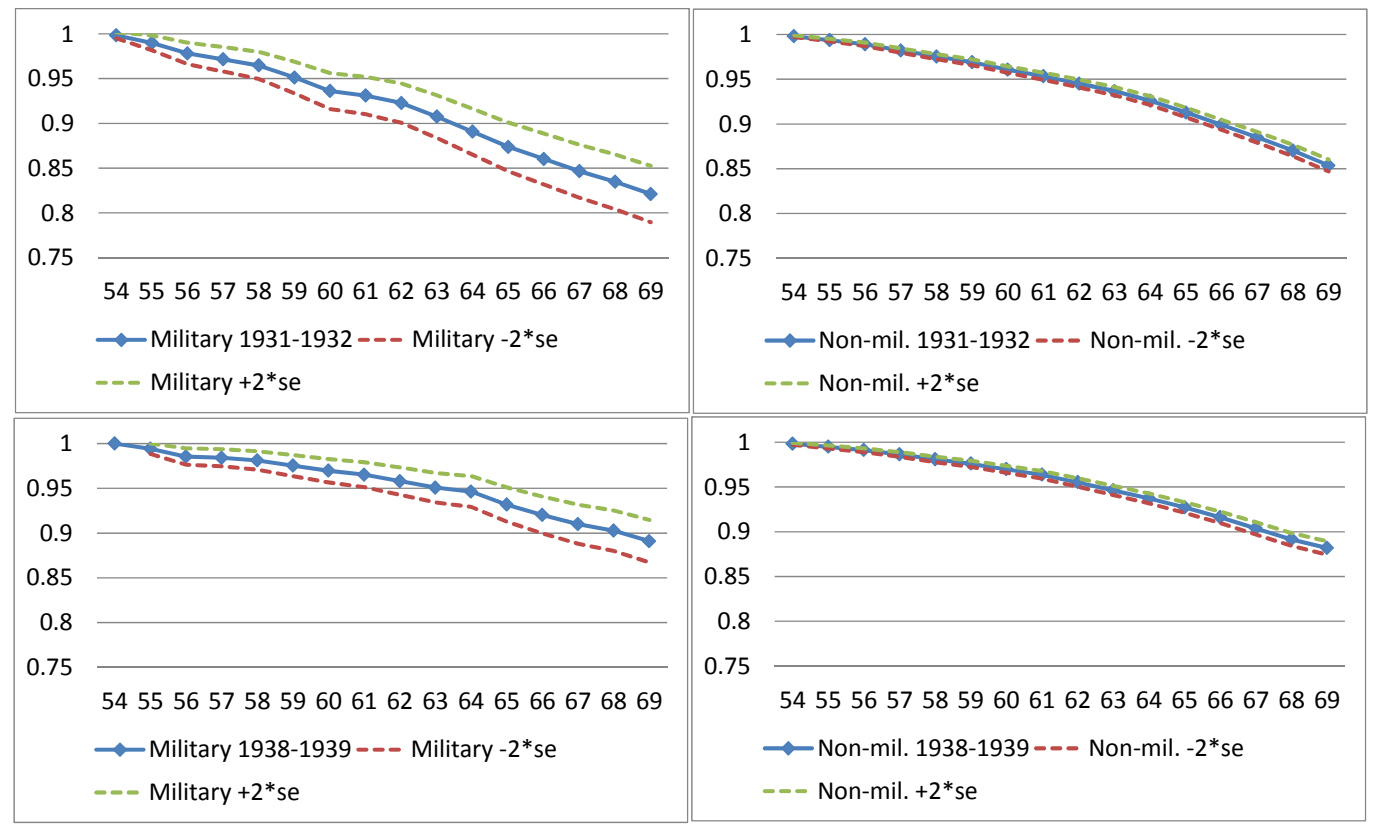

Figure 9: Kaplan-Meier estimates of the survival function, calculated by group 